\title{
III. Auf der Suche nach einem Profil (1927-1932)
}

Die Tatsache, daß Pfeilschifter seinen Posten als Präsident der Gesamtakademie bereits auf der zweiten Hauptversammlung, die im Oktober 1927 in München stattfand, an den renommierten Münchener Internisten Friedrich von Müller abtreten mußte, war ein deutliches Zeichen dafür, daß die Dinge in der jungen Organisation nicht zum besten standen. Auf dieser Hauptversammlung wurde u.a. der Antrag eingebracht, die praktische Abteilung solle sich zukünftig mehr den Auslandsdeutschen und dem Kulturexport ins Ausland widmen und weniger der Betreuung der Ortsgruppen in Deutschland. ${ }^{1}$ Die Akademie griff diesen Vorschlag auf, indem sie im Herbst 1927 beschloß, sich geographisch in der Kulturarbeit vor allem auf Südosteuropa zu konzentrieren und dem kulturellen Kontakt zu den nichtdeutschen Völkern des Balkans, der seit der Gründung mehr oder weniger zugunsten der Auslandsdeutschen vernachlässigt worden war, mehr Aufmerksamkeit zu widmen. ${ }^{2}$

\section{Hinwendung zum Balkan}

Als ersten Schritt in diese Richtung lud die Akademie im Juni 1928 eine zwölfköpfige jugoslawische Delegation von Wissenschaftlern, hohen Verwaltungsbeamten und Vertretern der südslawischen Wirtschaft zu einer zweiwöchigen Informationsreise nach Deutschland ein. Diese verlief zwar nicht ohne Spannungen zwischen den kroatischen, slowenischen, serbischen und volksdeutschen Reiseteilnehmern, wurde aber von der Akademie als ermutigendes Signal gewertet, daß der Balkan ein vielversprechendes Betätigungsfeld sein werde. Die Gespräche mit den Delegationsteilnehmern deuteten Thierfelder und Fehn so, daß Jugoslawien einzig mit deutscher Hilfe zu einem homogenen Staatsgebilde zusammenwachsen könne, da Frankreich nur eigennützige Hilfe leiste und seine "Formalkultur" von der Mehrheit der Südslawen abgelehnt werde. „Unterstaatssekretär Jelić sprach es unter Zustimmung der anderen geradezu einmal aus, daß nach Ansicht weiter Kreise auf dem Balkan in einigen Jahren Südosteuropa wirtschaftlich wie intellektuell Deutschland wie eine reife Frucht in den Schoß fallen werde. "Deutsche Firmen müßten allerdings nach Aussagen der Delegationsmitglieder zukünftig mehr sprachlich und landeskundlich vorgebildete Vertreter aus dem Reich entsenden und dürften nicht, wie bislang, auf die Vermittlerdienste der in Jugoslawien wenig

1 Bericht über die 2. Hauptversammlung der Deutschen Akademie 1927, in: MdDA, 2 (1927), S. 727-749, hier S. 749.

2 BAB R51/1, Protokoll der Mitarbeiterbesprechung, 7. 11. 1927. 
geliebten Ungarn und Österreicher zurückgreifen. ${ }^{3}$ Ermutigt durch den Erfolg der ersten Reise organisierte die Deutsche Akademie 1929 eine Informationstour bulgarischer Honoratioren durch Deutschland.

Die Akademie, im Grunde genommen im Kampf um die finanziellen Ressourcen der Kulturpolitik durch ihre Entfernung vom Entscheidungszentrum Berlin benachteiligt, konnte bei einer Fokussierung auf den Balkan ihre abgelegene geographische Lage in einen Vorteil ummünzen: Man präsentierte München als Tor nach Südosteuropa, als eine Stadt, die dank ihres angeblich südlichen Flairs den Balkanvölkern, sei es ihren Studenten oder den Angehörigen von Reisedelegationen, entgegenkomme. München erwecke auch, wie Rohrbach schrieb, gerade weil es nicht politisches Zentrum Deutschlands sei, bei den Ausländern weniger Mißtrauen, daß die von Bayern ausgehende Kulturwerbung direkte politische Ziele verfolge. ${ }^{4}$ München als Tor zum Südosten zu präsentieren, war im übrigen keineswegs eine originelle Idee der Deutschen Akademie. Auch hier erhielt sie Konkurrenz in Gestalt der im Juni 1930 in der bayerischen Landeshauptstadt errichteten „Stiftung zur Erforschung des Deutschen Volkstums im Süden und Südosten“, kurz „Süd-Ost-Institut“ genannt, die vom Reichsinnenministerium finanziell gefördert wurde.

Innerhalb der Akademie wurden im Jahre 1928 Überlegungen zur Gründung eines Balkaninstituts ${ }^{5}$ in München angestellt, das sowohl deutsche Spezialisten für diesen Großraum ausbilden wie auch ausländischen Stipendiaten vom Balkan aufnehmen sollte. Das 1928 ebenfalls kurzzeitig in die Diskussion gebrachte Projekt eines Ostseeinstituts der Deutschen Akademie hingegen, das wohl vor allem einem Wunsch des Baltendeutschen Rohrbach entsprang, sollte von vornherein in einer norddeutschen Großstadt angesiedelt werden. Beide Vorhaben wurden allerdings schon aus finanziellen Gründen nie ernsthaft in Angriff genommen. Sie waren vielmehr Ausdruck der Ende der zwanziger Jahre weitergehenden, tastenden Versuche der Akademie, sich in der wissenschaftlichen wie auslandskulturpolitischen deutschen Landschaft irgendwie zu positionieren.

Auch die wissenschaftliche Abteilung leitete mit dem Abgang Onckens im Oktober 1929 eine stärkere Ausrichtung ihrer Tätigkeit auf den Balkan ein. Im Januar 1930 trat eine Kommission zusammen, welche auf Beschluß der Hauptversammlung in Jena im Herbst 1929 neue Richtlinien für die künftige Arbeit ausarbeiten sollte. Sie beschloß, die unter der Präsidentschaft Onckens angefangenen Großeditionsprojekte zwar zu Ende zu führen, sich aber künftig auf die Erforschung der deutschen Kultur in Südosteuropa zu konzentrieren und von der Förderung von Einzeluntersuchungen, die nicht von den Sektionen betreut wurden, nach

3 BHStA Nachlaß Heinrich Held Bd. 1110, Bericht Thierfelders und Fehns über die von der Deutschen Akademie veranstaltete Studienreise südslawischer Wissenschaftler und Wirtschaftsvertreter durch Deutschland, Sommer 1928.

4 BAK N1408/124, Vorschläge für die Arbeit der Deutschen Akademie, Denkschrift Rohrbachs von 1930. Die geographische Lage Münchens wurde auch beim Rückblick auf die ersten 10 Jahre der Existenz der Deutschen Akademie 1935 als Grund für ihre starke Ausrichtung auf Südosteuropa angeführt. Vgl. Zehn Jahre Deutsche Akademie 1925-1935, in: MdDA, 10 (1935), S. 173-196, hier S. 179.

5 NStAOl Best 271-147680, Niederschrift der Sitzung des Kleinen Rates, 3. 9. 1928. 
Möglichkeit abzusehen. ${ }^{6}$ Ausdruck dieser neuen Schwerpunktsetzung waren in der Folgezeit Werke wie die "Quellen zur deutschen Siedlungsgeschichte in Südosteuropa“, die "Geschichte des deutschen Theaters in Ungarn“ oder die „Deutsche Landwirtschaft im Banat und in der Batschka"?

Mit der Fokussierung auf den Balkan folgte die Deutsche Akademie dem vom Auswärtigen Amt verfolgten Kurs, sich angesichts begrenzter Mittel auf jene Länder zu konzentrieren, die im Gesamtkonzept der deutschen Außenpolitik eine einigermaßen wichtige Rolle spielten und in denen man zugleich von vornherein mit einer recht großen Aufnahmebereitschaft für deutsche Kultur rechnen konnte. ${ }^{8}$ Zugleich entsprach natürlich die Entdeckung des Balkans als zukünftigem kulturpolitischen Hauptbetätigungsfeld der Deutschen Akademie der generellen Stoßrichtung deutscher auswärtiger Politik seit Ende der zwanziger Jahre. Der Balkan wurde seit dem Vorabend des Ersten Weltkrieges als ein Großraum gesehen, in dem Deutschland gute Chancen hatte, zunächst wirtschaftlich wie kulturell und langfristig auch politisch zur dominierenden Macht aufzusteigen und sich ein „informal Empire“ aufzubauen. ${ }^{9}$ War das Interesse an einem deutsch dominierten „Mitteleuropa“, zu dem der Balkan zählen würde, in der LocarnoÄra zwischenzeitlich etwas abgeflaut, so nahm es Ende der zwanziger Jahre in der Öffentlichkeit und in den Reichsministerien wieder deutlich zu. Die Kolonialmächte Frankreich und Großbritannien besannen sich im Zuge der Weltwirtschaftskrise auf ihre Kolonialreiche in der Hoffnung, durch eine engere, vor allem wirtschaftliche Kooperation mit den Überseegebieten mehr oder weniger autarke Großräume zu schaffen, welche die Mutterländer von den Unwägbarkeiten des Weltmarkes schützen würden. Ähnliches erhoffte sich das Deutsche Reich mit seiner Balkanpolitik, die vornehmlich als Außenhandelspolitik betrieben wurde. Die agrarisch strukturierten Balkanländer, deren Exporte nach Westeuropa und Übersee stark unter der durch die Weltwirtschaftskrise allgemein zu verzeichnenden Tendenz zum Protektionismus litten, waren ideale Lebensmittel- und Rohstofflieferanten für Deutschland und im Gegenzug Absatzmärkte für seine Industrieprodukte. In Deutschland hegte man geradezu übertriebene Erwartungen in eine

6 NStAOl Best. 271-14/680, Unterlagen für den Jahresbericht und die Verhandlungen der wissenschaftlichen Abteilungen auf der Hauptversammlung 1930. Vgl. auch Bericht über die 6. Hauptversammlung 1932, in: MdDA, 7 (1932), S. 415-444, hier S. $416 \mathrm{f}$. (Bericht Meyers über die seit 1929 eingetretenen Veränderungen in der Arbeit der wissenschaftlichen Abteilung).

7 Franz Wilhelm und Joseph Kallbrunner, Quellen zur deutschen Siedlungsgeschichte in Südosteuropa, München 1932; Jolantha von Pufansky-Kadar, Geschichte des Deutschen Theaters in Ungarn, Bd. 1: Von den Anfängen bis 1812, München 1930; Dr. Dammang, Deutsche Landwirtschaft im Banat und in der Batschka, München 1931.

8 Fritz von Twardowski, Anfänge deutscher Kulturpolitik zum Ausland, Bad Godesberg 1970, S. 25.

9 Jürgen Elvert, Der Balkan und das Reich. Deutsche Südosteuropapläne zwischen den Weltkriegen, in: Der Balkan. Eine europäische Krisenregion in Geschichte und Gegenwart, hrsg. von Jürgen Elvert, Stuttgart 1997, S. 133-180; Hans-Paul Höpfner, Deutsche Südosteuropapolitik in der Weimarer Republik, Frankfurt/M. u.a. 1983 sowie Hans-Jürgen Schröder, Deutsche Südosteuropapolitik 1929-1936. Zur Kontinuität deutscher Außenpolitik in der Weltwirtschaftskrise, in: Geschichte und Gesellschaft, 2 (1976), S. 5-32. 
handelspolitische Expansion gen Südosten. Das Interesse am Balkan wurde um so stärker, je mehr Deutschland von der Weltwirtschaftskrise erfaßt wurde und sich in der Ära Brüning von einer engen Kooperation mit dem Westen abwendete. Es wurde daher auch besonders in den anti-westlich eingestellten Zirkeln der Konservativen Revolution, etwa im sogenannten Tat-Kreis, propagiert. Für diese sollte die geographische Neuausrichtung der deutschen Außenpolitik mit einer inneren politischen Umgestaltung des Reichs einhergehen, da sowohl Deutschland wie auch die Balkanstaaten als junge, angeblich nicht vom westlichen Liberalismus und Industriekapitalismus angekränkelte Nationen angesehen wurden. ${ }^{10}$ Zugleich aber war der Balkan auch ein politisch umkämpftes Terrain, in dem man insbesondere mit französischer und italienischer hauptsächlich politischer und kultureller, weniger ökonomischer Konkurrenz zu rechnen hatte. Kulturelle Kontakte wurden in Berlin wie München als ein ergänzender Hebel gesehen, um den eigenen Einfluß auszudehnen und die westeuropäische, vor allem durch die Kleine Entente vorhandene starke bündnispolitische französische Präsenz zurückzudrängen.

Die von München ab 1928/29 ausgehenden kulturellen Initiativen, die sich also in die allgemeine Stoßrichtung deutscher auswärtiger Politik seit Ende der zwanziger Jahre einordneten, zielten vor allem auf Jugoslawien, Bulgarien und Griechenland ab. Ungarn, obwohl in den handelspolitischen Prioritäten des Auswärtigen Amts zunächst ebenso wie Rumänien noch vor Jugoslawien, Bulgarien und Griechenland rangierend, sah man in München als ehemaliges Kernland der Donaumonarchie als so deutschfreundlich an, daß man hier keine ausländische Konkurrenz zu fürchten brauchte. Rumänien, obwohl handelspolitisch ebenfalls umworben, betrachtete man hingegen als traditionell so stark dem französischen Kultureinfluß unterliegend und fest im Kielwasser der französischen Politik segelnd, daß es sich vorerst nicht zu lohnen schien, die ohnehin bescheidenen Mittel der Deutschen Akademie hier zu verschwenden.

\section{Die Frage des zukünftigen Kurses: Thierfelder versus Rohrbach}

Ermutigt durch die ersten Weichenstellungen zu einer klareren Ausrichtung der Arbeit seit Ende 1927 und zugleich besorgt um die nach wie vor mangelnde Zugkraft des Namens Deutsche Akademie im In- wie Ausland, bemühten sich sowohl Rohrbach wie auch Thierfelder im Jahre 1928, der praktischen Abteilung ein deutlicheres Profil zu geben. Dies war nicht zuletzt notwendig, um die weitere Finanzierung des gesamten Unternehmens sicherzustellen, das sich zunächst gänzlich aus Spenden aus der Wirtschaft und den Ortsgruppen erhalten mußte. Thierfelder, obwohl bei Aufnahme seiner Arbeit in München durchaus der Sache der Auslandsdeutschen zugeneigt, trat ab 1928 konsequent für eine Konzentration der

10 Sontheimer, Antidemokratisches Denken, S. 234 f.; Breuer, Anatomie der Konservativen Revolution, S. $105 \mathrm{f}$. 
Arbeit zumindest der praktischen Abteilung auf das Ausland im eigentlichen Sinne ein. Er erblickte hierin die einzige Chance, der Akademie eventuell auch Gelder aus den Kassen des Reiches sichern zu können.

Gefördert wurde dieses Überdenken der Rolle und Aufgabe der Akademie wesentlich durch den „Deutschen Schutzbund“ und dessen Vorsitzenden Karl Christian von Loesch. Der Deutsche Schutzbund war im Mai 1919 ins Leben gerufen worden, um bei den laut Versailler Vertrag anstehenden Volksabstimmungen in den deutschen Grenzgebieten unter den Wählern Werbung im Sinne des Reichs zu betreiben. Nachdem Anfang der zwanziger Jahre die letzten Volksabstimmungen stattgefunden hatten, suchte der Schutzbund sich ein neues Betätigungsfeld, indem er sich mehr und mehr als eine Art Dach- und Koordinierungsinstitution für alle Deutschtumsverbände präsentierte. ${ }^{11}$ Von Loesch, seit 1922 Vorsitzender des Schutzbundes, war zugleich seit 1925 Senator der Deutschen Akademie und aktives Mitglied der „Berliner Freunde der Deutschen Akademie“. Mit dem Schutzbund bestanden folglich von Anfang an gute und enge Beziehungen. Diese rührten zum einen daher, daß man mit dem vornehmlich politisch agierenden Schutzbund nicht auf kulturellem Gebiet konkurrierte. Sie lagen zum zweiten darin begründet, daß dem Schutzbund in München großer Einfluß auf die Reichsregierung zugeschrieben wurde. ${ }^{12}$ Tatsächlich erfreute sich zumindest von Loesch, der dem eher gemäßigten Flügel innerhalb des Schutzbundes angehörte, bei Reichsaußenminister Stresemann eines guten Rufes, ${ }^{13}$ während der Schutzbund insgesamt in den Reichsministerien eher kritisch beurteilt wurde. Er galt als zu nationalistisch und gefährdete damit in den Augen des Auswärtigen Amts wie des Reichsinnenministeriums die Politik gegenüber den Staaten, in denen es starke deutsche Minderheiten gab. In den Ministerien, in denen seit 1928 Sozialdemokraten an der Spitze standen, wie dem Reichsinnenministerium, galt er zudem als Sammelbecken anti-republikanischer Kräfte, da der Schutzbund u.a. den Verantwortlichen für die Ermordung von Karl Liebknecht und Rosa Luxemburg, Major Waldemar Pabst, durch einige Auftragsarbeiten finanziell unterstützt hatte. Insgesamt jedenfalls war der Schutzbund eindeutig gegen die Republik eingestellt. Dies zeigte sich u. a. daran, daß Jung ihn 1932 als einen jener Sammelpunkte konservativ-revolutionären, antidemokratischen Denkens lobte, welcher in der Vergangenheit den Weg für den Aufstieg der nationalsozialistischen Bewegung geebnet habe. ${ }^{14}$

11 Vgl. Dorothea Fensch, Zur Vorgeschichte, Organisation und Tätigkeit des Deutschen Schutzbunds in der Weimarer Republik. Ein Beitrag zur Geschichte des deutschen Revanchismus, Diss. phil. Universität Rostock 1966 sowie Grundmann, Deutschtumspolitik, S. $184-197$ und S. 431-447.

12 So Thierfelder in seinem Schreiben vom 20.6. 1928 an die Präsidenten der Deutschen Akademie, in: NStAOl 271-14/677.

13 So nahm Stresemann von Locsch gegenüber Reichsinnenminister Carl Severing in Schutz. Gerade unter von Loesch habe der Schutzbund eine den Reichsinteressen durchaus förderliche Politik eingeschlagen. Stresemann beklagte sich über die „vielfach irrigen Auffassungen“, die über den Deutschen Schutzbund kursierten. PA Bd. R60321, Brief Stresemanns an Severing, 24. 7. 1929.

14 Sontheimer, Antidemokratisches Denken, S. 35. 
Von Loesch hatte schon bei einem „Bierabend“ in München im März 1926, auf dem die wichtigsten Vertreter der Akademie versammelt waren, darauf hingewiesen, daß Südosteuropa ein lohnendes Tätigkeitsfeld sei und man die dortigen Journalisten beeinflussen könne, indem man für sie Sprachkurse einrichte. ${ }^{15} \mathrm{Im}$ Jahre 1927 veranstaltete der Schutzbund vier Konferenzen, um mit den anderen Deutschtumsverbänden eine einheitliche Linie der Politik gegenüber den deutschen Minderheiten zu formulieren und eine Aufgabenverteilung in der Arbeit zum Ausland vorzunehmen. Die erste Konferenz in Frankfurt/Oder widmete sich den deutschen Minderheiten in Nordosteuropa, die zweite in Cham dem Südosten, die dritte in Dresden den Sudetendeutschen und die vierte in Wien schließlich den Österreichern. Sie gipfelten in der vom Auswärtigen Amt finanziell geförderten „Berliner Schlußbesprechung“ vom 14. bis 17. März 1928, an der Vertreter der Deutschtumsverbände im Reich, der Auslandsdeutschen, Parlamentarier, Beamte diverser Reichsressorts sowie Repräsentanten der Industrie teilnahmen. Unter den insgesamt versammelten 170 Personen vertraten Präsident von Müller und Geschäftsführer Fehn die Deutsche Akademie. Auf dieser letzten Konferenz kam man überein, daß es eine europäische Kultur nur als Summe der Einzelkulturen gebe. Ziel jeglicher Kulturarbeit solle nicht die Vermengung der Kulturen sein, sondern Ausgleich unter bewußter Wahrung der Eigenarten der einzelnen Völker. Als Mittel des Kulturaustausches wie der wirtschaftlichen Annäherung empfahl die Versammlung u.a. die Abhaltung von Sprach- und Handelskursen im Ausland. Außerdem wurde gefordert, daß Kulturarbeit zum Ausland sich künftig nicht nur auf den Erhalt des Auslandsdeutschtums beschränken solle, vielmehr müsse dieses stärker als Mittler deutscher Kultur zu den nichtdeutschen Völkern im ost- und südosteuropäischen Raum hervortreten. ${ }^{16}$

Thierfelder, inspiriert und ermutigt durch die „Berliner Schlußbesprechung“, wandte sich zehn Tage später mit einer, wie er hervorhob, auf eigene Initiative und ohne Absprache mit von Müller verfaßten Denkschrift an das Auswärtige Amt. Er plädierte in dieser für eine deutliche Schwerpunktverlagerung in der Arbeit der Deutschen Akademie, weg von der bisherigen Konzentration auf die Förderung der Auslandsdeutschen. ${ }^{17}$ Auf der Berliner Tagung, so Thierfelder in einem Anschreiben an den stellvertretenden Leiter der Kulturabteilung, Hermann Terdenge, sei eine dringende Zentralisierung der deutschen Kulturpolitik zum nichtdeutschen Ausland gefordert worden. Von Loesch habe vorgeschlagen, daß die praktische Abteilung der Deutschen Akademie zukünftig Zentralstelle aller kulturellen Beziehungen zum nichtdeutschen Ausland werden solle. Die Deutsche Akademie sei, so Thierfelder in seinen beigefügten „Vorschlägen zur Organisation einer Zentralstelle für Auslandswerbung bei der Deutschen Akademie“, hierzu in besonderem Maße berufen wegen ihres eindrucksvollen Senates und der im ganzen Land verteilten Ortsgruppen. Zudem habe sie durch ihren Hauptsitz in Mün-

15 NStAOl Best. 271-14/679, Protokoll über den ersten Semester-Bierabend der Deutschen Akademie am 20.3.1926.

16 PA Bd. R60319, Berliner Schlußbesprechung vom 14. bis 17.3. 1928 des Deutschen Schutzbundes und der Deutschtumsverbände.

17 PA Bd. R 61124, Brief Thierfelders an Terdenge, 26. 3. 1928. 
chen den Vorteil, für das Ausland weniger als Instrument der Reichsregierung zu erscheinen. Zwar sei als Folge der Niederlage von 1918 eine Schwerpunktverlagerung der deutschen Außenpolitik von einer militärisch zu einer kulturell fundierten zu verzeichnen, doch könne man die bisherige Auslandskulturpolitik nur als ein erstes Tasten ohne inneren Zusammenhang bezeichnen. Die richtigen Methoden seien erst noch zu finden, wobei man das französische Modell nicht einfach kopieren, aber wegen seiner unbestrittenen Wirksamkeit studieren solle. Thierfelder plädierte dafür, daß Auslandskulturpolitik unbedingt in die Hände privater Organisationen gelegt werden müsse. Eine von einer Privatorganisation durchgeführte Kulturwerbung rufe bei den Empfängern weniger Mißtrauen hervor. Sie vermeide zugleich unnötige Bürokratisierung, die ohnehin Feind jeder Entfaltungsfreiheit sei, welche gerade die kulturelle Betätigung erfordere. Zugleich baute Thierfelder einen Köder ein, der seine Denkschrift für die Adressaten, wie die Unterstreichungen im Text der in den Akten der Kulturabteilung erhaltenen Kopie zeigen, besonders interessant machte: Die mit der Organisation der Kulturarbeit zum Ausland zu beauftragende private Stelle dürfe nicht eigenen, von der Staatspolitik unabhängigen Wegen folgen. „Im Gegenteil: je freier sie in der Durchführung ihrer Aufgaben ist, um so stärkerer Einfluß ist der politischen Leitung auf die allgemeine Marschrichtung einzuräumen." Kulturpropaganda um ihrer selbst willen sei zwar ideal gedacht, aber eine Utopie, da die Wirkung jeder Kulturarbeit im Ausland letztlich doch vom dahinterstehenden wirtschaftlichen und politischen Gewicht des Ausgangsstaates abhänge, vor allem bei der breiten Masse. Das Recht des Staates auf die Beeinflussung der Auslandspropaganda sei auch deshalb unbestreitbar, da nur er die finanziellen Mittel liefern könne. Nur die von ihm bereitgestellten Mittel würden gewährleisten, daß bei der Kulturarbeit ein allgemeinpolitisches Interesse wahrgenommen werde, während Privatpersonen und Verbände stets egoistische Zwecke verfolgten. Dies war also eine, wohl vor allem aus finanziellen Notwendigkeiten bedingte vollkommene Umkehr der Prämisse, unter der die Deutsche Akademie ihre Arbeit drei Jahre zuvor gestartet hatte, hatte sie doch gerade auf die Förderung durch Privatpersonen gesetzt, um von staatlicher Einflußnahme frei zu sein. Für jede Auslandspropaganda, so fuhr Thierfelder fort, gelte der Grundsatz der Gegenseitigkeit. Die Einflüsse des Auslandes müßten aber so gelenkt werden, daß die fremde Kultur die deutsche zwar befruchte, aber nicht verwässere.

An praktischen Vorschlägen forderte Thierfelder zum einen die Errichtung eines „Presseamtes“. Dieses sollte im ganzen Reich Presseagenten unterhalten, die in den deutschen Zeitungen Meldungen über kulturelle Vorgänge im Ausland lancieren und somit den Deutschen die Augen über die kulturellen Aktivitäten anderer Staaten öffnen würden. Das Presseamt würde zudem dazu beitragen, die Deutschen im Umgang mit anderen Völkern zu erziehen, vor allem dem deutschen Touristen gute Manieren beizubringen. Als zweites forderte er die Errichtung eines „Deutschtumsamtes“, das den eigentlichen Kulturexport ins Ausland zu organisieren habe. Dabei dachte Thierfelder an Konzerttourneen, Vortragsreisen bedeutender Wissenschaftler, Theatergastspiele, den Buchversand, die Werbung für Deutschland als Reiseziel sowie die Betreuung namhafter Ausländer in Deutschland. 
Die Denkschrift dürfte im Auswärtigen Amt als überambitioniert hinsichtlich des skizzierten Tätigkeitsfeldes der zu errichtenden „Zentralstelle für Auslandswerbung" eingeschätzt worden sein, zumal die Deutsche Akademie bei den Reichsministerien ohnehin nicht sonderlich beliebt war. Wenn das Auswärtige Amt zu diesem Zeitpunkt eine Zentralstelle favorisiert hätte, so wäre es sicherlich eher der Ende 1924 entstandene Akademische Austauschdienst gewesen, Vorläufer des Ende 1930 offiziell gegründeten DAAD. Er besaß vor allem durch seinen Vorsitzenden Adolf Morsbach enge Kontakte zu den Reichsressorts und wurde von Anfang an finanziell vom Reich erheblich unterstützt. Zudem eröffnete er schon 1927 eine Außenstelle in London. ${ }^{18}$ Immerhin aber hatte Thierfelder den Kontakt zur Kulturabteilung etabliert. ${ }^{19} \mathrm{Er}$ empfahl sich vor allem dadurch als zukünftiger Kooperationspartner, daß er die Richtlinienkompetenz der staatlichen Organe für die auswärtige Kulturpolitik ausdrücklich herausgestellt hatte. Terdenge antwortete ihm, indem er für die Zusendung der Denkschrift, die ihn sehr interessiert habe, dankte und daran die Hoffnung knüpfte, Thierfelder alsbald einmal in Berlin treffen zu können. ${ }^{20}$

Thierfelder versuchte nicht nur durch seine eigenmächtige Kontaktaufnahme zum Auswärtigen Amt eine Kurskorrektur und damit Rettung für die vom Scheitern bedrohte Deutsche Akademie zu bewirken. Er trat auch innerhalb der Akademie für eine Abkehr von der Ausrichtung der Arbeit auf das Auslandsdeutschtum ein. In einem Schreiben an die Präsidenten der Akademie im Juni 1928 wies er darauf hin, daß es auf dem Gebiet der eigentlichen Auslandswerbung, also der Kulturpropaganda gegenüber Nichtdeutschen, anders als auf dem Gebiet der Deutschtumsarbeit, keine Konkurrenz gebe. Einzig die vom Zentrumspolitiker Professor Georg Schreiber im Vorjahr in Münster gegründete „Forschungsstelle für Auslandsdeutschtum und Auslandskunde" betätige sich auf diesem Gebiet, und zu diesem bestünden ohnehin gute Kontakte. Thierfelder führte zur Unterstützung seines Standpunktes eine Unterredung mit von Loesch ins Feld, die er kurz zuvor gehabt habe. In dieser habe von Loesch hinsichtlich der zukünftigen Betätigung der wissenschaftlichen Abteilung eine stärkere Beschäftigung mit den Auslandsdeutschen in den vormaligen Gebieten der Habsburgermonarchie empfohlen und für die praktische Abteilung eine stärkere Konzentration auf die Kulturarbeit gegenüber Nichtdeutschen vorgeschlagen. Würde die Akademie eine solche klarere Ausrichtung ihrer Arbeit vornehmen, könne sie laut von Loesch auch Berliner Stellen für sich interessieren. ${ }^{21}$

Rohrbach hingegen, im Baltikum geboren und damit selbst Auslandsdeutscher, wollte nach wie vor zweigleisig fahren, also neben einer stärkeren Hinwendung zu nichtdeutschen Völkern zumindest die Betreuung wissenschaftlicher Einrichtungen der Auslandsdeutschen durch die praktische Abteilung fortführen lassen,

18 Laitenberger, Akademischer Austausch und auswärtige Kulturpolitik, S. $16 \mathrm{ff}$.

19 Frühere Kontakte zwischen Thierfelder und dem Auswärtigen Amt sind zumindest in den erhaltenen Akten nicht belegt.

20 PA Bd. R61124, Brief Terdenges an Thierfelder, 24. 4. 1928.

21 NStAOl Best. 271-14/677, An die Herrn Präsidenten der Deutschen Akademie, Schreiben Thierfelders vom 20.6. 1928 . 
wobei nach wie vor der Ostseeraum wie Südosteuropa gleichermaßen berücksichtigt werden sollten. Eine Aufzeichnung von Ende 1928 über die „Aufgaben der praktischen Abteilung der Deutschen Akademie“ stellte wohl den Versuch eines Kompromisses zwischen den Vorstellungen Thierfelders und Rohrbachs dar, auf den man sich in der Akademie vorerst einigte. 22 Demzufolge sollten 35000 RM jährlich - bei einem Gesamtetat der Akademie von etwa 100000 RM wäre dies der bei weitem größte Haushaltsposten gewesen - für die wissenschaftlichen Bedürfnisse des Auslandsdeutschtums bereitgestellt werden. Dies bedeutete vor allem die Fortführung der Förderung von Einrichtungen wie dem Brückentahlmuseum in Hermannstadt in Siebenbürgen und dem Herderinstitut in Riga. Weiterhin sollte die praktische Abteilung den Besuchsaustausch vor allem mit Delegationen vom Balkan fortführen, Stipendien für bereits akademisch vorgebildete Ausländer zu weiterführenden Studien in Deutschland bereitstellen, Büchersendungen ins Ausland vornehmen, eine Art Deutschlandhandbuch für Ausländer vorbereiten und allgemein an der wirksamen Organisation der Kulturwerbung zum Ausland arbeiten, da diese bisher von keiner anderen Institution betrieben werde. ${ }^{23}$

$\mathrm{Daß}$ man trotz Rohrbachs Vorstellungen den Ostseeraum und das nördliche Osteuropa Ende der zwanziger/Anfang der dreißiger Jahre in der Akademie weitgehend aus den Augen verlor und anfing, sich entsprechend Thierfelders Vorstellungen mehr dem Ausland im engeren Sinne zu widmen, verdeutlichte die Einrichtung sogenannter Länderausschüsse innerhalb der praktischen Abteilung ab 1928. Sie waren Komitees von bis zu zwei Dutzend anerkannten deutschen Experten für die jeweiligen Länder und Regionen. Die Ausschüsse sollten die Kenntnisse über die entsprechenden Zielgebiete in Deutschland vermehren und den Austausch mit diesen Ländern intensivieren. In manchen Ausschüssen saßen auch ausländische Gelehrte des betreffenden Landes. Bis Mitte der dreißiger Jahre hatten sich ein Amerika-, England-, China-, Japan-, Siam-, Indien-, Südafrika- und ein Südost-Ausschuß konstituiert. Für das nördliche Osteuropa und Skandinavien hingegen wurden bis zur Auflösung der Akademie nie eigene Ausschüsse eingerichtet. Allerdings tagten diese Länderausschüsse ebenso wie die wissenschaftlichen Sektionen nicht regelmäßig und waren eher eine eindrucksvolle Fassade als daß sie sichtbare Ergebnisse vorweisen konnten. Die Ausschüsse seien, so hieß es auf der Jahresversammlung 1932, nicht nach einem bestimmten Schema gebildet, sondern in ihrer Gliederung ganz auf die Bedürfnisse der einzelnen Länder ausgerichtet. Sie hätten weder Satzung noch Geschäftsordnung. ${ }^{24}$ Am aktivsten waren der 1928 eingerichtete und stark besetzte Indische Ausschuß und der 1934 gegründete Südost-Ausschuß. Der Indische Ausschuß konstituierte sich als permanente Organisation mit dem Namen „India Institute der Deutschen Akade-

22 Rohrbach wies in seinem Brief vom 27.11. 1928 an Oncken auf seine wie auch Thierfelders Denkschrift zur Neuausrichtung der Arbeit der Akademie hin, die beide unbedingt diskutiert werden müßten. Sie sind allerdings nicht mehr erhalten. In: NStAOl Best. 271$14 / 469$.

23 NStAOl Best. 271-14/680.

24 Bericht über die 6. Hauptversammlung der Deutschen Akademie 1932 in München, in: MdDA, 6 (1932), S. 415-444, hier S. $425 \mathrm{f}$. 
mie“. Ihm präsidierte bis 1937 Haushofer. Bis Kriegsausbruch ermöglichte er etwa zwei Dutzend indischen Studenten und Forschern den Aufenthalt in Deutschland. Noch stärker als der indische Ausschuß trat aber der sich dem Balkan widmende Südost-Ausschuß hervor. Er hatte als einziger eine eigene feste Arbeitsstelle in der Hauptgeschäftsstelle der Akademie und verfügte dort auch über eine Spezialbibliothek. Seine Arbeit schlug sich seit 1934 in einem monatlichen Informationsbulletin nieder, dem „Südost-Bericht“, das ab 1937 unter dem Titel „Stimmen aus dem Südosten" weiter geführt wurde. Das Organ enthielt aktuelle Nachrichten und Analysen aus der Region mit einem besonderen Augenmerk auf die Aktivitäten anderer Länder in diesem Raum. Der Südost-Ausschuß ließ auch einige Bücher aus der Region ins Deutsche übersetzen, gab eine Schriftenreihe über die einzelnen südosteuropäischen Staaten heraus und setzte sich für die Einrichtung von Lektoraten für die Sprachen des Balkans an deutschen Universitäten ein.

\section{Förderung der deutschen Sprache als kulturpolitische Nische}

Thierfelder, unterstützt durch den Vorsitzenden des Deutschen Schutzbundes, war also ab 1928 die treibende Kraft bei dem Versuch, die künftige Arbeit der Akademie regional auf den Balkan und dabei vor allem auf die dortigen nichtdeutschen Völker auszurichten. Langfristig entscheidender für die gesamte Entwicklung der Akademie sollte aber noch eine andere Weichenstellung werden, an der er zusammen mit von Loesch und gefördert vom Auswärtigen Amt ebenfalls maßgeblich beteiligt war. Diese sollte ab 1929 die Arbeit der praktischen Abteilung immer stärker prägen und in den dreißiger Jahren zu ihrem Tätigkeitsmerkmal schlechthin werden: die Konzentration auf die Förderung der deutschen Sprache im Ausland.

„Sprachwerbung“, der damals zumeist verwendete Begriff für ein Teilgebiet der auswärtigen Kulturpolitik, für das sich heute die Bezeichnung "Sprachförderung“ eingebürgert hat, ${ }^{25}$ hatte sowohl in der Planungsphase der Akademie in den Jahren 1923-1925 wie auch in der Auslandsarbeit der Akademie in den ersten Jahren ihrer Existenz keine Rolle gespielt. Beim Anschreiben der Deutschen Akademie an die deutschen Kultusminister im Frühjahr 1925 war die Verbreitung der deutschen Sprache überhaupt nicht als Betätigungsfeld für die praktische Abteilung aufgeführt worden. Bei der ungefähr zur gleichen Zeit entstandenen „Einführung in den Plan der Deutschen Akademie", die der Einladung zur Gründungsversammlung beigefügt war, wurde Sprachwerbung nur beiläufig als einer unter vielen Gesichtspunkten genannt. ${ }^{26}$ Die 1926 eingerichteten Sprachkurse der Deutschen Akademie für ausländische Studenten an der Münchener Universität, die in

25 Sprachförderung impliziert nicht nur Versuche der Verbreitung einer Sprache, sondern auch Maßnahmen zu ihrem Erhalt in Gebieten, auf denen sie im Rückzug begriffen ist. Vgl. Ulrich Ammon (Hrsg.), Sprachförderung. Schlüssel auswärtiger Kulturpolitik, Frankfurt/M. u. a. 2000.

26 Jacobsen, Haushofer, Bd. 2, Dokument 22 (hier S. 43) und Dokument 24 (hier S. 49). 
den zwanziger Jahren nach der Berliner Universität die meisten nichtdeutschen Studenten zählte, waren nicht einer Initiative der Zentrale, sondern der Münchener Ortsgruppe entsprungen. Daß die praktische Abteilung sich zunächst überhaupt nicht um die Möglichkeiten der Verbreitung der deutschen Sprache im Ausland kümmerte, war allerdings nicht verwunderlich, da ja die Aufmerksamkeit der Akademie zunächst vornehmlich den Auslandsdeutschen galt. Zudem war der Gründerzirkel der Deutschen Akademie, der sich vor allem aus Professoren der Münchener Universität zusammensetzte, noch ganz von der vor 1914 unumstrittenen Stellung der deutschen Sprache als der neben Englisch dominierenden Wissenschaftssprache geprägt. ${ }^{27}$ Mithin setzte er also eher die Kenntnis der deutschen Sprache voraus, als daß ihm ihre Verbreitung als Voraussetzung für den Zugang zur deutschen Kultur notwendig erschien.

Vielleicht hat Thierfelder sich von dem 1927 erschienenen Buch von Karl Remme und Margarete Esch über die französische Kulturpropaganda beeinflussen lassen, galt doch seit dem Kaiserreich, erst recht aber in der Weimarer Republik, die französische auswärtige Kulturpolitik als Modell einer erfolgreichen Beeinflussung des Auslandes schlechthin. In diesem Buch hieß es, „Kulturpropaganda ist in erster Linie Sprachpropaganda. Diese Wahrheit hat man in Frankreich begriffen. Im Zeichen der Sprachpropaganda steht die gesamte Kulturpolitik mit ihren vielgestaltigen Maßnahmen. "28 Die Weichenstellung hin zur Spracharbeit ist aber ebenfalls ganz wesentlich auf den Einfluß des Deutschen Schutzverbundes zurückzuführen, der im Zuge seiner Koordinationsbemühungen 1927/28 versuchte, die Deutsche Akademie auf ein klar umrissenes, von anderen Organisationen vernachlässigtes Gebiet der Kulturpolitik zu führen. Da auf den vom Schutzbund seit 1927 organisierten Konferenzen ohnehin die Forderung erhoben worden war, die deutsche Sprache mit Hilfe der Auslandsdeutschen in Ost-, Zentralund Südosteuropa zur innereuropäischen Verkehrssprache aufzubauen, ${ }^{29}$ lag es nahe, Ausschau nach einer Organisation zu halten, die diese Aufgabe wahrnehmen konnte.

1957 erwähnte Thierfelder in einer Ansprache an die Mitarbeiter des wiedergegründeten Goethe-Instituts, daß von Loesch ihn seinerzeit anläßlich einer Unterhaltung mehr oder weniger zufällig auf die Idee gebracht habe, „ob man nicht in den Ländern der ehemaligen österreichisch-ungarischen Monarchie Wirtschaftskurse einrichten sollte, in denen neben deutschem Unterricht Lehrgänge für Schreibmaschine, Stenographie, Warenkunde u.ä. zu treiben sei; dieses Bedürfnis müsse befriedigt werden, wenn die Beziehungen zu dem deutschsprachigen Mitteleuropa nicht völlig verloren gehen sollten. " 30 Diese Unterhaltung mit langfristigen Folgen für die Entwicklung der Deutschen Akademie dürfte irgendwann zwischen April und Juni 1928 stattgefunden haben. Denn in seiner Denkschrift an das Auswärtige Amt vom März 1928, die eine Reaktion auf die Berliner Schlußbe-

27 Vgl. hierzu Ulrich Ammon, Die internationale Stellung der deutschen Sprache, Berlin u.a. 1991 , S. $251 \mathrm{ff}$.

28 Karl Remme und Margarete Esch, Die französische Kulturpropaganda, Berlin 1927, S. 21.

29 Grundmann, Deutschtumspolitik, S. 435.

30 Franz Thierfelder, 25 Jahre deutsche Sprachpolitik im Ausland, S. 225. 
sprechung war, führte Thierfelder unter den Methoden der Kulturarbeit im Ausland die Förderung der Deutschen Sprache noch nicht auf. In seiner Denkschrift vom Juni 1928 an die Präsidenten der Deutschen Akademie hingegen verwies er bereits auf ein Gespräch mit von Loesch, in dem dieser darauf hingewiesen habe, daß die Zukunft der Deutschen Akademie auf dem Balkan und hier insbesondere in der Kulturpolitik gegenüber nichtdeutschen Völkern liege. Ein weiteres Indiz spricht dafür, daß das Frühjahr 1928 als Beginn der Beschäftigung mit Fragen der Sprachförderung innerhalb der Akademie anzusehen ist. In Thierfelders erstem Aufsatz über die internationale Stellung der deutschen Sprache stammen sämtliche von ihm bei den Auslandsmissionen des Reiches und bei Deutschlehrern im Ausland eingeholten und im Aufsatz zitierten Auskünfte aus dem Zeitraum Juni bis September 1928,31 so daß die Versendung entsprechender Fragebögen im Frühjahr 1928 begonnen haben dürfte. Es erscheint plausibel, von Loesch die Urheberschaft für die Idee der Sprachförderung als zukünftigem Betätigungsfeld der Deutschen Akademie zuzuschreiben, da dieser ja bereits 1926 im Rahmen einer Veranstaltung der Akademie auf die Möglichkeit der Einrichtung von Sprachkursen auf dem Balkan hingewiesen hatte. Auch bei der „Berliner Schlußbesprechung" im März 1928 waren von ihm Sprach- und Wirtschaftskurse als Instrumente der Kulturwerbung vorgeschlagen worden.

Daß Thierfelder selbst nicht von Anfang an Sprachförderung als Betätigungsfeld der Deutschen Akademie im Sinn hatte, geht aus seiner letzten Denkschrift als Generalsekretär der Akademie im Dezember 1937 hervor. Diese war eine Art Rechenschaftsbericht über seine Tätigkeit seit den zwanziger Jahren, in der er sich gegen Kritik innerhalb der Akademie verteidigte, die vor allem von Professoren in den Sektionen der wissenschaftlichen Abteilung geäußert worden war. Für diese war offenbar die wissenschaftliche Akademie mittlerweile zu einer bloßen „Sprachschule“ herabgesunken:

„Es ist nicht so, wie vielleicht jemand denken könnte, daß ich mein besonderes Steckenpferd zum Steckenpferd der Deutschen Akademie gemacht hätte. Als ich zur Deutschen Akademie $\mathrm{kam}$, hatte ich mich bis dahin weder mit der deutschen Sprachwerbung befaßt noch diese als Aufgabe der Deutschen Akademie erkannt. Erst im Laufe der Jahre ist die Konzentrierung der praktischen Arbeit auf die Sprachwerbung als Notwendigkeit erwachsen, und es gehört vielleicht auch zu den Erfordernissen unserer Zeit, daß eine lebensnahe wissenschaftliche Organisation den Mut besitzt, sich zu dieser Wirksamkeit ganz zu bekennen. “32

Der Einfluß des Vorsitzenden des Deutschen Schutzbundes auf die ab 1927 einsetzenden Bemühungen innerhalb der Akademie, dieser ein klareres Tätigkeitsprofil angedeihen zu lassen, das letztlich in einer Konzentration auf die Förderung der deutschen Sprache im Ausland mündete, kann also als sehr hoch angesehen werden.

Thierfelder war für die Idee der Förderung der deutschen Sprache im Ausland insofern empfänglich, als sein berühmter Vorfahre Thomasius sich Ende des

31 Franz Thierfelder, Deutsch im Unterricht fremder Völker, in: MdDA, 3 (1928), S. 10151056.

32 BAB R8043/1331, Erläuterungen zu dem Entwurf des Haushalts 1938 der Deutschen Akademie, Aufzeichnung Thierfelders vom 12. 12. 1937. 
17. Jahrhunderts dafür eingesetzt hatte, Deutsch als Sprache in der Wissenschaft zu verwenden und es dazu als erster Universitätslehrer in Deutschland wagte, Vorlesungen in der Muttersprache abzuhalten. Der Gedanke, sozusagen in der Tradition der Familie den Kampf für die Verbreitung der deutschen Sprache nunmehr außerhalb der Reichsgrenzen aufzunehmen, so wie es Thomasius über zweihundert Jahre zuvor für ihre Durchsetzung in Deutschland getan hatte, dürfte Thierfelders beginnende Aktivitäten auf dem Gebiet der Förderung der deutschen Sprache sicherlich nicht gerade gebremst haben. Er widmete sich dieser für ihn zunächst gänzlich neuen Aufgabe, die ihn jedoch bis an sein Lebensende nicht mehr losließ, alsbald mit seiner ganzen Energie. Als ersten Schritt begann er im Frühjahr 1928, vermutlich ausgelöst durch die vom Deutschen Schutzbund lancierte Forderung, Deutsch als innereuropäischer Verkehrssprache Geltung zu verschaffen, im Namen der Deutschen Akademie mit einer systematischen Erhebung über den Stand des Deutschunterrichts und der Verbreitung der deutschen Sprache in der Welt. Er wollte damit, wie er 1929 schrieb, „der Deutschen Akademie erst einmal einen Rechtstitel geben, sich dieser Arbeit im besonderen annehmen zu können ". ${ }^{33}$ Er schrieb u. a. die deutschen Auslandsmissionen sowie Hochschullektoren und Deutschlehrer im Ausland an. Die Ergebnisse seiner sprachstatistischen Bemühungen veröffentlichte er, laufend aktualisiert, zunächst in sechs Aufsätzen in den Jahren 1928-1936 in den „Mitteilungen der Deutschen Akademie“34, 1938 schließlich in Teilen in seinem Buch mit dem programmatischen Titel „Deutsch als Weltsprache“35. Die sprachstatistischen Erhebungen Thierfelders waren für die damalige Zeit hinsichtlich ihres Umfanges zumindest für Deutschland einzigartig. ${ }^{36}$

Bereits auf den ersten Seiten des ersten Aufsatzes, der Ende 1928 in den „Mitteilungen" veröffentlicht wurde, entwickelte Thierfelder eine Art Programm zukünftiger kulturpolitischer Betätigung. Bevor er an eine Bestandsaufnahme der Stellung der deutschen Sprache in den einzelnen Ländern ging, wies er auf die groBen Vorteile hin, die Frankreich aus seiner systematischen Sprachpolitik in der Vergangenheit auf internationaler Bühne gezogen habe. Er argumentierte aber zugleich, daß im Grunde genommen die Dominanz der französischen Sprache in Europa überholt sei: Ihre beherrschende Stellung habe kein solides Fundament mehr, da sie nur noch durch ein überproportioniertes Instrumentarium auswärtiger Kulturpolitik aufrechterhalten werde, ihre Rolle aber nicht mehr den tatsäch-

33 BHStA Nachlaß Heinrich Held Bd. 1110, Die Pflege der deutschen Sprache im Ausland als Arbeitsgebiet der Deutschen Akademie, Denkschrift Thierfelders vom Sommer 1929.

34 Franz Thierfelder, Deutsch im Unterricht fremder Völker, in: MdDA, 3 (1928), S. 10151056; ders., Deutsch im Unterricht fremder Völker II, in: MdDA, 4 (1929), S. 4-48; ders., Deutsch im Unterricht fremder Völker III, in: MdDA, 5 (1930), S. 215-255; ders., Deutsch im Unterricht fremder Völker IV, in: MdDA, 6 (1931), S. 338-364; ders., Deutsch im Unterricht fremder Völker V, in: MdDA, 8 (1933), S. 298-342 sowie ders., Deutsch als Weltsprache. Die Entwicklung der deutschen Sprache im nichtdeutschen Ausland seit der nationalsozialistischen Revolution, in: MdDA, 11 (1936), S. 5-69.

35 Franz Thierfelder, Deutsch als Weltsprache, Bd. 1: Die Grundlagen der deutschen Sprachgeltung in Europa, Hamburg 1938. Band 2 ist nicht erschienen.

36 Ammon, Die internationale Stellung der deutschen Sprache, S. 4 und 6. 
lichen ökonomischen, demographischen und politischen Gegebenheiten Nachkriegseuropas entspreche. Die Rede von einem bereits im Abstieg begriffenen Frankreich, das eine Rolle auf der internationalen - nicht nur kulturpolitischen Bühne spiele, die seinen Ressourcen und seiner kulturellen Ausstrahlungskraft eigentlich nicht mehr entspreche, war im übrigen ein ressentimentgeladenes Klischee, das unter den Intellektuellen der Weimarer Republik weitverbreitet war und im Dritten Reich geradezu zum Dogma wurde. ${ }^{37}$ In dieses Horn stieß im Jahre 1928 auch Thierfelder in sprachpolitischer Hinsicht:

„Es soll gezeigt werden, daß sich nach dem Kriege eine zunehmende Kenntnis des Deutschen auf der ganzen Welt feststellen läßt, daß in dem Maße, als die Pflege des Französischen abzubröckeln beginnt, die Bevorzugung des Deutschen (und Englischen) als Fremdsprache im Schulunterricht teilweise erstaunlich voranschreitet, und daß sich bereits heute Deutsch in seiner internationalen Stellung in einzelnen Gebieten sogar vor ihm behauptet. Berücksichtigt man vollends, daß sich diese Entwicklung in einer Zeit politischer und wirtschaftlicher Ohnmacht vollzogen hat und noch vollzieht, so darf man in kulturpolitischer Hinsicht vertrauensvoll vorwärts blicken. “38

Als besonders vielversprechendes Tätigkeitsfeld bezeichnete er dabei, im Einklang mit der sich abzeichnenden geographischen Ausrichtung der gesamten Arbeit der Akademie, den Balkan: „Hier ist das Ringen um Sprachgeltung unter $\mathrm{Na}$ tionen, die zur Weiterbildung ihrer eigenen Sprachen und Kulturen entschlossen sind, besonders heftig, aber auch besonders aussichtsreich. Denn der Balkan mit seinem Gemisch aus verschiedenen Rassen braucht eine Verkehrssprache, wie staunenswert sich auch im Laufe der Jahrhunderte die Fähigkeit der Bewohner in der Erlernung vieler Sprachen entwickelt hat." Diese Sprache, so Thierfelders selbstredende Schlußfolgerung, konnte aus geschichtlichen wie geopolitischen Gründen nur die deutsche sein. Allerdings sei ihre dortige traditionelle Vormachtstellung seit dem Ende des Ersten Weltkrieges durch das Französische, Englische und Italienische bedroht, so daß dringender Handlungsbedarf bestehe. ${ }^{39}$

Thierfelder lieferte in den folgenden Jahren mehrere Gründe dafür, warum man hinsichtlich der Zukunft der deutschen Sprache in Europa und anderswo optimistisch sein dürfe: Der Widerstand Deutschlands gegen eine übermächtige Gegnerkoalition im Weltkrieg, sodann die Entdeckung Deutschlands als preisgünstiges Reiseland in den Zeiten der Inflation, schließlich auch seine wirtschaftliche Gesundung seit Mitte der zwanziger Jahren habe im Ausland, insbesondere in den USA, zu einem verstärkten Interesse am Deutschen geführt. Der Balkanraum und Osteuropa, nach dem Ende der Donaumonarchie, des Zarenreiches und des Os-

37 Vgl. Hans Manfred Bock, Tradition und Topik des populären Frankreichklischees in Deutschland von 1925 bis 1955, in: Francia, 14 (1986), S. 475-508. Explizit gab Thierfelder seiner Überzeugung, daß Frankreich seinen kulturpolitischen Zenit überschritten habe, zwei Jahre später Ausdruck: „Das den Franzosen kennzeichnende mangelnde Verständnis für fremde Wesensart wurde durch unübertreffliche Geschicklichkeit in der Menschenbehandlung ausgeglichen. Und doch ist der Höhepunkt der kulturellen Vormachtstellung Frankreichs in der Welt heute zweifellos überschritten." Zitiert aus Thierfelder, Geistige Grundlagen kultureller Auslandsarbeit, S. 227.

38 Thierfelder, Deutsch im Unterricht fremder Völker I, S. 1016.

39 Franz Thierfelder, Deutsche Spracharbeit in Südosteuropa, in: MdDA, 4 (1929), S. 262272, hier S. 263. 
manischen Reiches in eine Reihe neuer Nationalstaaten zerfallen, brauche eine lingua franca, zu der sich Deutsch aus historischen, demographischen und geographischen Gründen besonders eigne. Auch bei den Auslandsdeutschen, die z.T. erst durch Repressalien im Ersten Weltkrieg oder durch die Diskriminierung in den neuen Nationalstaaten Ost- und Südosteuropas sich ihrer Wurzeln bewußt geworden seien, sei ein stärkeres Sprachbewußtsein zu verzeichnen. Zudem gebe es bestimmte Bevölkerungsgruppen und politische Bewegungen, die sich ebenfalls des Deutschen oder verwandter Sprachen bedienten und damit wichtige Vorarbeit zur Verbreitung des Deutschen leisteten. Hierzu zählte Thierfelder einmal die stark von Deutschen geprägte kommunistische Internationale, vor allem aber das osteuropäische Judentum mit seinem Jiddisch, ja selbst das Afrikaans der Buren und die Mundarten deutschen Ursprungs, welche die nach Nord- und Südamerika ausgewanderten religiösen Minderheiten sprachen. ${ }^{40} \mathrm{Schließlich,} \mathrm{und} \mathrm{das} \mathrm{war}$ vielleicht der Hauptgrund für Thierfelders sprachpolitischen Optimismus, verkörperte für ihn die deutsche Sprache auch im Gegensatz zu den anderen großen europäischen Sprachen das „völkische“ Prinzip, also eine spezifische Form der Freiheit, der gesellschaftlichen Harmonie und des Widerstands gegen den verhaßten Liberalismus westlicher Prägung. Dies waren weltanschauliche Prinzipien, die er als Anhänger der Konservativen Revolution nicht nur in Deutschland seit Ende der zwanziger Jahre auf dem Vormarsch sah, während doch die westliche Idee der universellen Menschenrechte und des Parlamentarismus, für welche das Französische und Englische stünden, überall im Rückzug begriffen sei. „Ist es denn nur in Deutschland ein Geheimnis, daß die Erlernung des Deutschen in allen Ländern der Erde nach dem Kriege in teilweise überraschendem Umfange zunimmt?", schrieb Thierfelder am 18. Mai 1932 in einem Artikel in der der DVP nahestehenden "Deutschen Allgemeinen Zeitung" und sprach im gleichen Atemzug vom „untergehenden materialistisch-rationalistischen Zeitalter". Hier trafen sich seine (sprach-)politischen Gedankengänge eindeutig mit jenen Jungs, der beinahe zeitgleich in der Juni-Ausgabe 1932 der "Deutschen Rundschau“ schrieb, daß

„die deutsche Sache zu einer europäischen gemacht werden muß, daß wir eine Sprache sprechen müssen, die nicht nur uns geläufig ist, sondern zum Herzen der zivilisierten Menschheit spricht. Unsere Sprache muß weltläufig werden dadurch, daß wir verstehen, die deutsche Sache zur Sache der Menschheit zu machen, eine Kunst, die den Franzosen 150 Jahre erfolgreicher Politik und den Sieg im Weltkrieg einbrachte. Es wäre falsch, zu diesem Zwecke eine kosmopolitische Sprache zu erlernen oder auszubilden, das Geheimnis ist, die deutsche Sprache - nicht im philologischen Sinne, sondern im geistigen Sinne - zur Weltsprache zu machen. Das ist aber nur möglich, wenn das deutsche Volk der Welt etwas schenkt, das sie in ihren Grundfesten erschüttert, die Herzen auflockert und den gepreßten Atem der kapitalistischen Menschheit vom Drucke befreit. Wer ein neues Ordnungssystem in das soziale und politische Sein hineinträgt, wird für die nächsten Jahrhunderte führen. Frankreich hat das Unglück, diesen Krieg gewonnen zu haben, sich auf Besitz versteifen zu müssen und das Rad der Geschichte aufhalten zu wollen. Wir haben das Glück, durch Zwang und Not gedrängt

40 Vgl. Thierfelder, Deutsche Spracharbeit in Südosteuropa; ders., Neue Wege zur Verbreitung der deutschen Sprache im Auslande, in: MdDA, 5 (1930), S. 14-40 sowie ders., Deutsch als Weltsprache, S. 40-42. 
zu werden, zum Quell wahren Menschtums zurückzukehren. Die neue Menschwerdung geht von uns oder niemand aus. " 41

An anderer Stelle konstatierte Jung etwa zur gleichen Zeit:

„Die Sprache der deutschen Revolution wird - bei aller und gerade wegen dieser nationalistischen Grundhaltung - eine weltläufige sein. Wir werden im Kampfe um unsere Selbsterhaltung zum ersten Male wieder eine Sprache sprechen, die zum Herzen aller Völker dringt. Denn die Sache der deutschen Revolution wird zur Sache aller Völker, die nicht wie Frankreich den Ablauf der Geschichte hemmen wollen, indem sie sich und ihr Geistesgut als abschließenden Höhepunkt aller Zeiten statuieren wollen. “42

Entsprechend schrieb Thierfelder einige Jahre später, Englisch habe zwar fast überall in Europa Französisch als dominierende Fremdsprache verdrängt, „aber sonst sehen wir vorerst nicht, was es geistig zum Neubau Europas, ja der Welt beizutragen hätte“. ${ }^{43}$

Thierfelder wies bereits Ende 1928 den Weg, den man in der Deutschen Akademie gehe solle: „Der letzte Sinn des Aufsatzes besteht darin zu zeigen, welche unabsehbaren Möglichkeiten für Deutsch gerade im gegenwärtigen Augenblick gegeben sind, durch zielbewußte Sprachpflege im Ausland die aus der jüngsten Zeit stammenden Vorurteile zu überwinden und ein neues Fundament für unsere kulturelle Weltgeltung zu legen." Da es wohl kaum möglich sei, Einfluß auf die Lehrpläne der fremden Staaten zu nehmen, so schloß der Artikel, müsse man zunächst darauf hinwirken, daß der Deutschunterricht im Ausland attraktiver gemacht werde. Ein Weg sei die Verteilung von Buchgeschenken an die besten Schüler im Ausland, die Versendung von leicht zu lesenden Zeitschriften, insbesondere Illustrierten, und die Entwicklung eines lebendigen und aktuellen Deutschlehrbuches. ${ }^{44}$ In den folgenden Artikeln versuchte er seine These von der ständig zunehmenden Bedeutung der internationalen Stellung der deutschen Sprache vor allem auf Kosten der französischen Sprache mit neuen Berichten aus dem Ausland zu untermauern. So schrieb er in Teil III seiner Erhebung, die im Sommer 1930 veröffentlicht wurde, seit der letzten zusammenfassenden Übersicht über den deutschen Unterricht im Ausland seien so viele erfreuliche Nachrichten über die Fortschritte auf diesem Gebiet eingegangen, daß ein Nachtrag zu den beiden früheren Aufsätzen angezeigt erscheine. In den wenigen Fällen, in denen die Nachprüfung früherer Angaben notwendig gewesen sei, habe es sich durchweg um Änderungen in einem für Deutschland günstigen Sinne gehandelt, „so daß der verschiedentlich beanstandete Optimismus unserer Übersicht seine Berechtigung erwiesen hat " ${ }^{4}{ }^{5}$

Thierfelders Erhebungen und Überlegungen zeitigten schon im Jahre 1928 bei der Deutschen Akademie Wirkung. Auf der Hauptversammlung im Oktober, also noch vor ihrer Veröffentlichung in den „Mitteilungen“, wurde bereits über die

41 Edgar Julius Jung, Neubelebung von Weimar?, in: Deutsche Rundschau, 58 (1932), S. 153162, Zitat S. 157.

42 Ders., Deutschland und die konservative Revolution, in: Deutsche über Deutschland. Die Stimme des unbekannten Politikers, München 1932, S. 369-381, Zitat S. 380.

43 Thierfelder, Deutsch als Weltsprache, S. 45.

44 Thierfelder, Deutsch im Unterricht fremder Völker I, S. 1017 (Zitat) und S. 1055.

45 Thierfelder, Deutsch im Unterricht fremder Länder III, S. 215. 
„überraschend positiven Ergebnisse“ der Erhebung berichtet und verkündet, daß man demnächst mit dem Versand von Illustrierten ins Ausland beginnen werde. ${ }^{46}$ $\mathrm{Daß}$ Thierfelders Argumente auf einen fruchtbaren Boden fielen, dürfte nicht zuletzt auch darauf zurückzuführen sein, daß sich mit der Spracharbeit ein Betätigungsfeld für die Deutsche Akademie eröffnete, das noch nicht von anderen Institutionen bearbeitet wurde. Mithin bot sich endlich die Möglichkeit, der Auslandsarbeit der Deutschen Akademie ein eigenes Profil zu verschaffen und damit womöglich auch staatliche Sponsoren zu finden. Im Auswärtigen Amt wurde man auf Thierfelders Vorhaben der Erstellung einer Sprachstatistik schon während der Phase der Materialsammlung aufmerksam, hatte er doch die Auslandsmissionen um Hilfe gebeten. Die Sprachstatistik und die daraus abzuleitenden sprachpolitischen Handlungsmaximen erschienen der Kulturabteilung als ein klar umrissenes und vielversprechendes Projekt. Es war also ein wesentlich realistischerer Vorschlag als Thierfelders Gedankengänge in der Denkschrift vom März 1928, in der er für die Deutsche Akademie schlichtweg die Führung in der nichtamtlichen Kulturpolitik zum Ausland reklamiert hatte. Ab 1929 erhielt die Deutsche Akademie vom Auswärtigen Amt regelmäßig Kopien von jenen Berichten der Auslandsmissionen, die sich mit sprachpolitischen Fragen beschäftigten, sowie von den bei der Kulturabteilung eingehenden Denkschriften im Ausland lebender Deutscher zu Stand und Entwicklung des Deutschunterrichts in einzelnen Ländern. Die Geschäftsstelle der Akademie in München entwickelte sich seit 1929 quasi zu einem im Auftrag der Wilhelmstraße arbeitenden sprachstatistischen Büro. ${ }^{47}$ Thierfelders Schilderung der erfolgreichen Kontaktaufnahme zur Kulturabteilung im Jahre 1928/29, die in einer Denkschrift aus dem Sommer 1929 überliefert ist, liest sich wie folgt: ${ }^{48}$

„Diese Arbeit fand die Aufmerksamkeit der Kulturabteilung des Auswärtigen Amtes, ich nutzte verschiedene Aufenthalte in Berlin, um mit den Herren der Kulturabteilung persönlich bekannt zu werden und arbeitete, als ich eine gewisse Geneigtheit für eine intensivere Behandlung der Sprachpflege im Ausland festgestellt hatte, eine längere Denkschrift mit praktischen Vorschlägen aus, die ich Geheimrat Terdenge einreichte. Dieser lud mich für mehrere Tage nach Berlin ein, um auch den anderen Herren der Kulturabteilung meine Vorschläge zu entwickeln, die sich zunächst, wie ich nachträglich erfahren habe, für eine Zusammenarbeit mit der Deutschen Akademie nicht geneigt gezeigt hatten. Es gelang mir, die Bedenken zu zerstreuen und Geheimrat Terdenge teilte mir mit, daß man grundsätzlich bereit sei, der Deutschen Akademie das ganze Gebiet der Sprachpflege, soweit es sich um die Arbeit unter Ausländern außerhalb der Propagandaschulen betreffe, zu überlassen, und hierfür auch die nötigen Mittel bereitzustellen."

46 Bericht über die 3. Hauptversammlung der Deutschen Akademie 1928, in: MdDA, 3 (1928), S. 1063-1083, hier S. $1069 \mathrm{f}$.

47 So bedankte sich Thierfelder beispielsweise am 5. 12. 1929 beim Auswärtigen Amt für die Zusendung eines Berichtes über den Stand des Deutschunterrichts in Chile, den ein deutscher Lehrer an die Kulturabteilung geschickt hatte (in: PA Bd. R 63806). Im vierten Teil seines Überblicks über den Deutschunterricht im Ausland zitiert er den Bericht eines deutschen Konsulates in Rumänien. Vgl. Thierfelder, Deutsch im Unterricht fremder Völker IV, S. 344.

48 BHStA Nachlaß Heinrich Held Bd. 1110, Die Pflege der deutschen Sprache im Auslande als Arbeitsgebiet der Deutschen Akademie, Denkschrift Tierfelders vom Sommer 1929. 
Allerdings nannte das Auswärtige Amt laut Thierfelder zwei Bedingungen: Die Zusammenarbeit müsse vertraulich bleiben, und die Durchführung sei an seine Person gebunden, „da man nach den letzten Erfahrungen (Schutzbund) nicht mit Organisationen, sondern Personen verhandeln wolle".49

Thierfelders ursprüngliche, beim Auswärtigen Amt eingereichte Denkschrift über die Intensivierung der Sprachförderung im Ausland, auf die er in der zitierten Passage Bezug nahm, ist nicht mehr erhalten, er griff jedoch im Sommer 1929 wieder einige seiner früheren Vorschläge auf. ${ }^{50}$ Thierfelders Grundidee war offenbar gewesen, die Sprachförderung bei den deutschen Hochschullektoren an ausländischen Universitäten zu zentralisieren, ein Vorschlag, der durch die zeitgleiche Konstituierung des DAAD in Berlin alsbald obsolet wurde, da dieser die Auswahl und Betreuung der Hochschullektoren monopolisierte. Die Hochschullektoren sollten nach Thierfelders Vorstellung künftig nicht mehr Einzelkämpfer sein, die individuell von den ausländischen Universitäten ausgewählt und angestellt wurden, sondern systematisch von Deutschland betreut und vor ihrer Ausreise ausgebildet würden. Sie sollten neben der Ausbildung der Deutschlehrer der Gastländer an den germanistischen Seminaren auch Sprachkurse außerhalb der Universitäten abhalten, auf den Deutschunterricht in den Schulen des Gastlandes einwirken, regelmäßig über die kulturpolitischen Aktivitäten von Drittstaaten berichten, sich für einen stärkeren Absatz deutschsprachiger Bücher einsetzen und Presse und Rundfunk des Gastlandes mit Informationen über Deutschland versorgen.

Im Auswärtigen Amt gedachte man, die bewährte Zusammenarbeit mit privaten oder halböffentlichen Einrichtungen, die sich auf dem Feld der Betreuung des Auslandsdeutschtums seit der Zeit vor dem Ersten Weltkrieg bewährt hatte, nun auch auf die Sprachförderung auszudehnen. Formal vom Amt unabhängige, sich kulturpolitisch betätigende Einrichtungen hatten mehrere Vorteile: Sprachförderung wie auch andere Aktivitäten waren kostengünstiger durch Vereine als durch Beamte zu betreiben. Zudem konnten Vereine scheinbar überparteilicher Natur private Spender besser zu Beiträgen animieren, ein nicht zu vernachlässigendes Argument angesichts der chronisch knappen Kassen des Weimarer Staates, die sich nicht zuletzt in der Kulturabteilung bemerkbar machten. Sodann gewährleisteten Privatorganisationen eine stärkere personelle Kontinuität als die dem Rotationsprinzip unterworfenen Beamten des Auswärtigen Amts. Schließlich suggerierte die Aktivität privater Organisationen im Ausland auch die Illusion einer relativen Staatsferne kultureller Initiativen und stieß daher möglicherweise bei den Empfängern auf weniger Vorbehalte, im Grunde genommen im Dienste außenpolitischer Ziele des Reichs zu stehen. Doch selbst wenn man, wie Kurt Düwell in seinem Standardwerk zur auswärtigen Kulturpolitik der Weimarer Republik schreibt, im Auswärtigen Amt gewillt war, der Kultur eine gewisse Autonomie zu gewähren und sie nicht nur als ein Mittel zur Erlangung machtpolitischer Ziele

49 Ebenda.

50 Ebenda. Einige der Gedankengänge finden sich auch bei Thierfelder, Deutsch im Unterricht fremder Völker II, S. $43 \mathrm{f}$. 
sah, ${ }^{51}$ so betrieb man sie doch in erster Linie nicht um ihrer selbst willen. Sie bewegte sich vielmehr stets im Rahmen der generellen politischen Zielvorgaben der damaligen deutschen Außenpolitik, welche auf eine Überwindung des Vertrags von Versailles und eine Wiederherstellung der deutschen Großmachtstellung hinzielte, wie sie vor dem Ersten Weltkrieg bestanden hatte. Zur Erlangung dieser Ziele konnten kulturelle Initiativen scheinbar wichtige Hilfsdienste leisten. Andernfalls wäre es unverständlich gewesen, warum das Auswärtige Amt Thierfelder bei der sich anbahnenden Zusammenarbeit zur Geheimhaltung verpflichtete und zunächst vor allem auf die Stärkung der deutschen Sprache auf dem Balkan abzielte, der seit Ende der zwanziger Jahre eine immer wichtigere Rolle im Rahmen der allgemeinen deutschen Außenpolitik einnahm.

In der Wilhelmstraße wollte man jedoch, bevor es an konkrete Schritte zur Sprachförderung ging, die Thierfelder vorgeschlagen hatte, zunächst einmal mehr über die Sprachsituation auf dem Balkan erfahren. „Die Besprechungen im Auswärtigen Amt haben damit geendet, daß ich inoffiziell beauftragt worden bin, auf einer Reise durch die Städte des Balkans die Anknüpfungen und Unterlagen zu schaffen, auf denen dann ein ins einzelne gehendes Programm der Sprachwerbung (Entsendung weiterer Lektoren, Einrichtung von Sprachkursen, Förderung fremdvölkischer Deutschlehrer usw.) durchgeführt werden kann", schrieb Thierfelder im Mai 1929 an Oncken. Vom 3. Juni bis 1. Juli 1929 absolvierte Thierfelder die erste Reise auf Kosten des Auswärtigen Amts, das ihm allerdings zugleich auferlegt hatte, daß seine Verbindungen nach Berlin in der Öffentlichkeit nicht bekannt werden sollten. ${ }^{52}$ Die Exkursion führte ihn nach Budapest, Belgrad, Sofia, Saloniki, Athen, Istanbul und Bukarest. Sie war der eigentliche Beginn von Thierfelders jahrzehntelanger intensiver Beschäftigung mit dem Balkan.

In seinem Abschlußbericht an das Auswärtige $\mathrm{Amt}^{53}$ sah er die Stellung des Deutschen in den Schulen und Universitäten Ungarns als führend und nicht durch andere Fremdsprachen gefährdet an. In Jugoslawien hingegen entspreche die Lage des Deutschunterrichts nicht dem bestehenden Interesse der Südslawen, vor allem slowenischer Wirtschaftskreise, und dem Stand der deutschen Sprache vor 1914, was vor allem auf das kulturpolitische Wirken Frankreichs zurückzuführen sei. Hinsichtlich Bulgariens schätzte Thierfelder die Situation als grundsätzlich günstig ein, da Deutsch schon an den Mittelschulen unterrichtet werde und es eine große Zahl privater Sprachkurse gebe. Problematisch sei hier eher die mangelnde

51 Düwell, Deutschlands auswärtige Kulturpolitik, S. $89 \mathrm{ff}$. Scholten, Sprachverbreitungspolitik des nationalsozialistischen Deutschlands, S. 39-42 unterzieht diese etwas idealistische Sichtweise Weimarer auswärtiger Kulturpolitik, die in Düwells Buch z.B. nicht an der konkreten Kulturpolitik in bestimmten Ländern und Regionen der Welt überprüft wird, einer überzeugenden Kritik. Die neue Untersuchung von Pöppinghaus, Moralische Eroberungen? kommt anhand einer Überprüfung der konkreten Kulturpolitik gegenüber einem speziellen Land ebenfalls zum Schluß, daß die von Carl Heinrich Becker 1919 erhobene Forderung einer Autonomie der Kulturpolitik von außen- und handelspolitischen Vorgaben während der Weimarer Republik kaum Niederschlag in der tatsächlichen Politik gegenüber Spanien fand.

52 NStAOl Best 271-14/680, Brief Thierfelders an Oncken, 13. 5. 1929.

53 PA Bd. R63806, Die Lage der deutschen Sprache auf dem Balkan - Ergebnisse einer Studienreise, Bericht Thierfelders vom Sommer 1929. 
fachliche Qualifikation der Deutschlehrer. In Griechenland sei der französische kulturelle Einfluß am stärksten, doch zugleich im Schwinden begriffen, so daß hier ein guter Ansatzpunkt für Deutschland sei. Allerdings bestehe in Griechenland eine Tendenz, sich gegen zu starke fremde kulturelle Einflüsse zunehmend abzuschotten. Für die Türkei bezeichnete Thierfelder die Stellung des Deutschen als sehr günstig, die alte Vorherrschaft des Französischen hingegen als erschüttert. In Rumänien sei noch gar nichts für die deutsche Sprache getan worden.

Auf einer zweiten, vom Auswärtigen Amt finanzierten Reise im November 1930 eruierte Thierfelder ganz konkret die Chancen zur Einrichtung von Sprachkursen der Akademie in Bulgarien und Jugoslawien. Es waren genau jene Länder, die laut Thierfelders erstem Reisebericht grundsätzlich der deutschen Sprache positiv gegenüberstanden, in denen es aber bislang Defizite gab. Zugleich waren es Länder, die in der Balkanstrategie des Auswärtigen Amts eine wichtige Position einnahmen, da sie die Brücke zum südlichen Balkan, dem Mittelmeer und zur Türkei bildeten. Nach Abschluß der zweiten Reise schrieb Thierfelder an das Auswärtige Amt: „Diese kurze Studienreise hat mich in meiner Überzeugung aufs neue bestärkt, daß für die deutsche Kulturarbeit im Ausland die südosteuropäischen Staaten das erfolgversprechendste Gebiet darstellen." Eines Tages werde man auch die wirtschaftlichen Früchte der kulturpolitischen Arbeit in diesem Raum ernten. „Aus diesem Grunde möchte ich zum Schluß immer wieder darauf hinweisen, wie notwendig es ist, durch aufklärende Arbeit in Deutschland selbst das Verständnis für die Balkanvölker zu mehren und ihre nationale Entwicklung in engste Verbindung zu unserer kulturellen Entwicklung zu bringen." 54

Thierfelder sah die Balkanstaaten als junge Nationen an, die auf der Suche nach einem starken Partner waren, der ihnen bei der Entdeckung ihrer kulturellen Wurzeln helfen konnte. Deutschland war in seinen Augen besonders geeignet, enge kulturelle Bande zum Balkan zu knüpfen, da es anders als Frankreich keine universalistische Zivilisationsidee exportiere, sondern eine "völkische“ Ideologie, die von der grundsätzlichen Unterschiedlichkeit und Unvereinbarkeit der Kulturen ausging und mithin zur Selbstfindung der noch jungen Nationen eher beitragen könne. „Es bedarf des Spiegels der fremden Nationen, um sich selbst noch besser zu erkennen, es braucht den kritischen oder befreundeten Zuruf, um seine eigenen Leistungen womöglich noch zu steigern und sich des eigenen Wertes täglich aufs Neue gewiß zu werden," verkündete Thierfelder auf der Hauptversammlung der Akademie im Oktober $1933 .{ }^{55} \mathrm{Er}$ zeigte sich damit als Jünger der damals dominierenden, erstmals von Arnold Bergsträsser explizit formulierten These der "kulturellen Begegnung“, die beim Deutschen Akademischen Austauschdienst, der in einer gewissen Konkurrenz zur Deutschen Akademie stand, die offizielle Doktrin zur Begründung auswärtiger Kulturarbeit war. Diese besagte, daß die kulturelle Begegnung zwischen den Nationen vor allem der Entdeckung der eigenen nationalen Züge diene, was durchaus beiden Seiten zum Vorteil gereichen

54 PA Bd. R64194, Bericht über meine Studienreise in Südosteuropa 10.-30. 11. 1930.

55 Franz Thierfelder, Deutsche Kulturpolitik im Ausland, Referat auf der Jahresversammlung der Deutschen Akademie im Oktober 1933, in: BHStA MK 40444. 
könne. ${ }^{56}$ Zugleich sah Thierfelder die Balkanvölker auch als weniger durch die von ihm kritisch gesehene westliche, industrielle und demokratische Zivilisation beeinflußt. Sie waren also natürliche Partner Deutschlands, das sich schon vor 1933 wieder vom Westen abzuwenden und einer autoritäreren Staatsform zuzuwenden schien. So lobte er in einem Vortrag vom November 1934 in Belgrad die slawischen Völker, die sich ein gesundes Bauerntum erhalten hätten, während Deutschland bis 1933 bereit gewesen sei, „vor der westlichen Zivilisation zu kapitulieren und fortschrittsgläubig die bäuerliche Stufe als überwundenen Zustand der Entwicklung anzusehen." Auf dem Balkan hingegen habe sich die Kraft zum Widerstand gegen die „technische Zerstörung der abendländischen Kultur" erhalten. ${ }^{57} \mathrm{Er}$ beklagte das Ungleichgewicht in der gegenseitigen Wahrnehmung: Leider würde man sich in Deutschland nach wie vor hauptsächlich für den Westen interessieren, aber kaum für den Balkan, obwohl gerade dort großes Interesse für Deutschland herrsche. ${ }^{58}$ Die geistige Affinität Thierfelders zur politischen Organisation und gesellschaftlichen Formation der Balkanstaaten, geopolitische Erwägungen und die Notwendigkeit, für die in München ansässige Deutsche Akademie eine auch in ihrer geographischen Ausrichtung überzeugende kulturpolitische Nische zu finden, waren die Hauptgründe dafür, daß er sich in den dreißiger Jahren immer mehr von seinem früheren Studienobjekt Skandinavien, dem er in seinen sächsischen Jugendjahren immerhin Studium und Promotion gewidmet hatte, ab- und einem neuen Großraum zuwendete. Auch nach dem Ausscheiden aus der Deutschen Akademie Ende 1937, als Thierfelder fortan als freier Autor seinen Lebensunterhalt verdienen mußte, versuchte er in einer regelrechten Flut von Veröffentlichungen das Interesse der deutschen Öffentlichkeit auf den Balkan zu lenken, auf dem seiner Ansicht nach ein politisches und kulturelles Engagement für Deutschland wesentlich lohnenswerter sei als in West- oder Nordeuropa. ${ }^{59}$

\section{Jahresversammlung in Jena 1929}

Als eigentlicher Wendepunkt für die Auslandsarbeit der Akademie, mit welchem eine künftige Förderung durch das Auswärtige Amt sichergestellt wurde, erwies sich die Hauptversammlung in Jena im Oktober 1929. Nicht nur sah sich die wissenschaftliche Abteilung unter Oncken dort kritisiert und wurde gezwungen, ihre

56 Arnold Bergsträsser, Sinn und Grenzen der Verständigung zwischen Nationen, Berlin 1930. Vgl. hierzu auch Laitenberger, Akademischer Austausch und auswärtige Kulturpolitik, S. 73-80.

57 Franz Thierfelder, Deutsche und Slawen, in: MdDA, 10 (1935), S. 25-39, hier S. 37.

$58 \mathrm{Vgl}$. Thierfelder, Deutsche Spracharbeit in Südosteuropa, S. 271.

59 Vgl. Franz Thierfelder, Um die Seele des Balkans. Kulturpolitisches Reisetagebuch, Berlin 1940; ders., Schicksalsstunden des Balkans, Wien 1940; ders., Der Balkan im europäischen Raum, Berlin 1941; ders., Der Balkan als kulturpolitisches Kräftefeld. Zwischenstaatliche Propaganda und geistiger Austausch in Südosteuropa, Berlin 21941; ders., Gestalten und Gestalter des Balkans, Berlin 1943; ders., Ursprung und Wirkung der französischen Kultureinflüsse in Südosteuropa, Berlin 1943. 
Forschungs- und Publikationstätigkeit zu überdenken. Den Vertretern des Senats und der Ortsgruppen war im Vorfeld durch das Wirken Thierfelders und von Loeschs sowie die Signale aus der Wilhelmstraße deutlich vor Augen geführt worden, daß die Deutsche Akademie dringend eines neuen und eindeutigeren Profils für die Auslandsarbeit bedürfe. Thierfelder hatte offenbar einen Kurswechsel zur Bedingung für seinen Verbleib in der Akademie gemacht. Dies geht aus einem Schreiben Haushofers vom August 1929 an Senator Pechel hervor. Ihm übersandte er einen (nicht mehr erhaltenen) Entwurf eines Antrages für die Senatssitzung auf der kommenden Hauptversammlung. Wenn dieser, so Haushofer, nicht angenommen werde, bedeute „es den Abgang des tüchtigen Thierfelder, wahrscheinlich auch Fehns, den Bruch mit dem Auswärtigen Amt und nebenbei einen Skandal" ${ }^{60}$ Soweit kam es jedoch nicht. Im November 1929 teilte Thierfelder dem Auswärtigen Amt mit, "Jena" sei so verlaufen, "daß mein weiterer Verbleib bei der Akademie vorläufig nicht in Frage gestellt ist" ${ }^{6}{ }^{61}$

Auf der Jenaer Jahresversammlung stellte der Reichstagsabgeordnete des Zentrums Georg Schreiber, Senator der Deutschen Akademie und nicht zuletzt wegen seines Sitzes im Haushaltsausschuß des Reichstages einer der einflußreichsten Kulturpolitiker in der Weimarer Republik, ${ }^{62}$ den Antrag, die kulturpolitische Arbeit der Deutschen Akademie gegenüber dem Ausland möge zukünftig weniger auf die Auslandsdeutschen als auf die Nichtdeutschen ausgerichtet werden, da es für die Betreuung der Auslandsdeutschen schon genügend andere Institutionen gebe. „Ihre Haupttätigkeit gilt jedoch der Pflege des deutschen Gedankens unter Ausländern; in zielbewußter Zusammenarbeit mit allen beteiligten Stellen wird die Deutsche Akademie die Verbreitung der deutschen Sprache im Auslande durch Errichtung von privaten Sprachkursen unter Zusammenarbeit von Professoren, Lektoren und Lehrern für die deutsche Sprache im Ausland zu fördern suchen." Daneben forderte Schreiber, zukünftig vermehrt Bücher und Zeitschriften ins Ausland zu versenden und die persönlichen Beziehungen zwischen deutschen und ausländischen Kreisen zu vertiefen, um damit das Verständnis für den Wert der deutschen Kultur im Ausland zu stärken und zugleich im Inland den Blick für die ausländischen Kulturinstitutionen zu schärfen. ${ }^{63}$ Fehn und Thierfelder flankierten diesen Antrag mit Vorträgen über „Fremde Kulturarbeit im Ausland“ und „Deutsche Sprachwerbung im Ausland“ .64

Fehns Vortrag griff den Topos auf, daß man in Deutschland vor dem Kriege die auswärtige Kulturpolitik vernachlässigt habe. Dies sei zwar mittlerweile bekannt, weniger bewußt sei man sich aber, daß die anderen Mächte, allen voran Frankreich, das „ungeheuere Mittel“ aufwende, auch nach 1918 kulturpolitisch aktiv geblieben seien. Selbst kleinere neue Staaten wie Polen, die Tschechoslowakei und

60 BAK N1160/I/71, Brief Haushofers an Pechel, 4. 8. 1929.

61 PA Bd. R64194, Schreiben Thierfelders an das Auswärtige Amt, 3. 11. 1929.

$62 \mathrm{Zu}$ Schreiber vgl. Rudolf Morsey, Georg Schreiber, in: Wissenschaftspolitik in Berlin. Minister, Beamte, Ratgeber, hrsg. von Wolfgang Treue und Karlfried Gründer, Berlin 1987, S. 269-284.

63 BHStA MA 100128, Antrag Schreibers für die Senatssitzung am 18. 10. 1928.

64 Kopien der beiden Vortragsmanuskripte befinden sich in: BAK N1160/I/142. 
Ungarn hätten sich kulturpolitisch zu Wort gemeldet, wenn auch eher dahingehend, daß sie versuchen würden, eine eigene Kultur aufzubauen und sich zugleich von fremden Einflüssen abzuschotten. „Wir dürfen die Augen vor den Deutschland dadurch drohenden Gefahren nicht verschließen. Deutschland darf von seiner kulturellen Weltgeltung nicht mehr weiter zurückgedrängt werden “, forderte Fehn. Andere Nationen hätten bisher besser erkannt, „daß ein Volk, das Weltgeltung genießen will, auch die Kenntnis und Wertschätzung seiner Art, seines Wesens, seines Wissens und seiner Leistungen auf kulturellem Gebiet durch andere Völker braucht, und daß sich aus dieser Kenntnis und Wertschätzung wirtschaftliche Folgen ergeben, die auch mit bester Reklame nicht erzielt werden können“. Allerdings machte Fehn seinen Zuhörern, die für eine neue Auslandskulturpolitik der Akademie gewonnen werden sollten, die sich nicht als Deutschtumspolitik gab, Mut: Sowohl im Auswärtigen Amt wie in der Wirtschaft beginne sich allmählich diese Erkenntnis Bahn zu brechen.

Thierfelder zeigte sodann in seinem Vortrag die Mittel, derer sich die Deutsche Akademie künftig bedienen sollte. Andere Länder seien Deutschland in Fragen der Auslandskulturpolitik mindestens zehn Jahre voraus, auch und vor allem in der Sprachpflege und Sprachpolitik. „Hier tut sich Neuland für unser Volk auf, hier stellt sich die Kernaufgabe der praktischen Abteilung der Deutschen Akademie, eine Aufgabe, deren Lösung zwar auf öffentliche Aufmerksamkeit und Anerkennung verzichten muß, dafür aber des Erfolges um so sicherer ist. Denn Deutschlands Zukunft in der Welt hängt nicht zuletzt davon ab, wieviele Menschen auf Erden Deutsch sprechen und verstehen werden." Merkwürdigerweise, so fuhr Thierfelder fort, habe bisher über den Grad der Verbreitung der deutschen Sprache im Ausland weitgehend Unkenntnis geherrscht. „Der Kampf gegen unsere Sprache nach dem Kriege, die bedauerliche Vorliebe der Deutschen, sich im Verkehr mit anderen Völkern jeder anderen Sprache eher als der eigenen zu bedienen und der unausrottbare Wahn, das Deutsche sei wegen seiner Schwierigkeit für die internationale Verständigung nicht geeignet, hatte eine Ungläubigkeit bezüglich der Auslandsgeltung des Deutschen groß werden lassen, die das schwerste Hemmnis für jede Spracharbeit darstellte." Nun lägen aber die Ergebnisse der Untersuchung über die internationale Stellung der deutschen Sprache gedruckt in den „Mitteilungen“ vor. Sie seien zwar verschiedentlich als schön gefärbt bezeichnet worden, er könne ,jedoch aus den Erfahrungen der letzten Monate erneut betonen, daß sich unsere zuversichtliche Beurteilung in vollem Umfange bestätigt hat". Thierfelder stellte sodann zwei Postulate auf, denen er während seiner ganzen Tätigkeit in der Akademie, also auch über 1933 hinaus, treu bleiben sollte: Grundlage der Auslandsarbeit müsse der Gedanke der Gegenseitigkeit sein und Kulturpolitik müsse offen arbeiten. „Vermeiden wir also alles, was den Schein des Geheimnisvollen und deshalb Hinterhältigen bei unserer Spracharbeit erwecken könnte; bei dem immer noch vorhandenen Mißtrauen der Welt gegen jede deutsche Auslandsarbeit ist rückhaltlose Offenheit das einzige Mittel, Vertrauen zu gewinnen. " Da Auslandskulturarbeit nur Erfolg habe, wenn man auch den Adressaten Gelegenheit zur Entfaltung ihrer Kultur lasse, plädierte Thierfelder zugleich für eine stärkere Förderung der Sprachen Ost- und Südosteuropas in Deutschland etwa durch Einrichtung entsprechender Hochschullektorate, da in diesen Län- 
dern das Interesse an der deutschen Sprache am größten sei. Eine slawische Sprache sollte seiner Auffassung nach auch an den deutschen Mittelschulen gelehrt werden. Zudem sei es angebracht, Französisch als erste Sprache an den deutschen Schulen zukünftig durch Englisch zu ersetzen, da Englisch überall auf dem Vormarsch, Französisch aber allgemein im Rückzug begriffen sei.

Mit sprachstatistisch scheinbar abgesicherten Argumenten und mit der Unterstützung Schreibers, von Loeschs und des Auswärtigen Amts im Rücken, war es nicht überraschend, daß sich Thierfelders Konzept, das die Förderung der deutschen Sprache unter Ausländern in den Vordergrund künftiger Aktivitäten der Deutschen Akademie rückte, im Oktober 1929 schließlich durchsetzte. Die Ereignisse in Jena waren zugleich eine Niederlage für Rohrbach, der bis dahin für die weitere Förderung auch des Auslandsdeutschtums durch die Akademie eingetreten war. Er wurde auf der Hauptversammlung auch nicht, wie er im Vorfeld erhofft und gefordert hatte, zum Präsidenten der praktischen Abteilung gewählt, sondern nur auf ein weiteres Jahr als geschäftsführendes Präsidialmitglied bestätigt. ${ }^{65}$ Es war ein deutliches Zeichen dafür, daß sein Einfluß in der Akademie nach dem Weggang Onckens im Schwinden begriffen war, während nun die Ära Thierfelder anbrach.

\section{Umdenken im Auswärtigen Amt}

Die Kulturabteilung des Auswärtigen Amts lernte Thierfelders Kooperationsbereitschaft, Ideenreichtum und Energie alsbald zu schätzen. So hieß es in einer Aufzeichnung der Kulturabteilung für den Reichsaußenminister vom Oktober 1930, der "Geschäftsführer" Thierfelder sei außerordentlich aktiv und umsichtig und arbeite in allen Fragen aufs engste mit dem Auswärtigen Amt zusammen.66 Thierfelder wiederum behauptete Mitte der dreißiger Jahre, als er mit dem neuen Akademiepräsidenten Haushofer in Konflikt geriet, das Auswärtige Amt habe in den Jahren 1929 bis 1933 lediglich ihm als Person, nicht jedoch der Akademie als Ganzes Vertrauen geschenkt. Nur durch dieses persönliche Vertrauensverhältnis zwischen ihm und der Wilhelmstraße sei der Aufbau der Spracharbeit der Akademie möglich gewesen. ${ }^{67}$

Die Förderung der deutschen Sprache im Ausland, der sich Thierfelder in München im Auftrage des Auswärtigen Amts 1928/29 anzunehmen begann, besaß in der Wilhelmstraße Ende der zwanziger Jahre eine etwa fünfzigjährige Tradition, deren Anfänge auf die Einrichtung eines Schulfonds im Jahre 1878 zurückgin-

65 Daß Rohrbach seinen dauerhaften Verbleib in der Akademie an die Forderung geknüpft hatte, in Jena zum Präsidenten der praktischen Abteilung gekürt zu werden, spiegelt sich in der Korrespondenz mit Oncken in den Jahren 1928/29 wider. Dieser Schritt wurde unter anderem durch den Akademiepräsidenten von Müller blockiert. In: NStAOl Best. 271-14/469.

66 PA Bd. R64194, Vorlage für den Reichsaußenminister, 15. 10. 1930.

67 BAK N1010/39, Brief Thierfelders an Senator Gerland, 24. 3. 1937. 
gen. ${ }^{68}$ Doch erst im letzten Jahrzehnt vor dem Ersten Weltkrieg gewann sie richtig Kontur. Nun achtete der neu eingestellte Schulreferent im Auswärtigen Amt, Franz Schmidt, erstmals systematisch darauf, daß an den "klassischen“ deutschen Auslandsschulen die Kinder ausgewanderter Deutscher oder vorübergehend im Ausland lebender Reichsangehöriger tatsächlich auch auf Deutsch unterrichtet wurden. Zugleich bemühte man sich, spezielle deutsche Schulen in den Gastländern für einheimische Schüler zu errichten, die sogenannten Reichsschulen für Ausländer. Ab 1909 hießen sie offiziell „Propagandaschulen“69. Allerdings entstanden von ihnen bis 1914 nur insgesamt 13 in China, der Türkei und Persien. Im Gegensatz zu den etwa 900 "klassischen“ Auslandsschulen, die überwiegend von den deutschen Auslandsvereinen vor Ort finanziert wurden, waren die „Propagandaschulen" ganz von Subventionen aus dem Reichshaushalt abhängig. Daneben richtete man auch an den Auslandsschulen Abenddeutschkurse für Erwachsene ein. ${ }^{70}$ Auch im VDA mehrten sich nach der Jahrhundertwende die Stimmen, daß man die Auslandsschulen nicht nur zum Erhalt des Deutschtums, sondern auch als Instrumente der Verbreitung deutscher Kultur und Sprache unter der nichtdeutschen Mehrheitsbevölkerung der jeweiligen Gastländer einsetzen solle. Allerdings setzte sich diese Auffassung nicht durch, da der selbstgestellte Auftrag, die auf 30 Millionen Mitglieder geschätzte deutsche Auslandsgemeinde vor der Assimilation zu schützen, bereits als eine derart große Herausforderung angesehen wurde, daß sie aller vorhandenen Energien und Ressourcen bedürfe. ${ }^{71}$ Fokus des VDA wie auch des Auswärtigen Amts blieben also bis 1918 vornehmlich die deutschen Minderheiten, die stets an ihre deutschen Ursprünge erinnert wurden und sich damit eine gewisse Loyalität zum Reich bewahren sollten.

Nach 1918 wurde diese sich vor dem Ersten Weltkrieg abzeichnende Politik, also die deutsche Sprache mittels deutscher Schulen auch unter fremdsprachigen Völkern zu verbreiten, aus Geldmangel wie auch aus Furcht, die Auslandsschulen dadurch in den Verdacht von Propagandazentren geraten zu lassen, weitgehend eingestellt. Die „Propagandaschulen“ verschwanden gänzlich, und auch die an den Schulen in der Vorkriegszeit eingerichteten Deutschkurse für Erwachsene wurden reduziert. ${ }^{72}$ Hatte das Auswärtige Amt vor 1914 z.B. Deutschsprachkurse an 58 Plätzen im Ausland gefördert, wobei die Türkei mit 31 und China mit zehn Standorten herausragten, so waren es in der ersten Hälfte der zwanziger Jahre nur noch insgesamt zehn Standorte, davon sechs in China und zwei in der

$68 \mathrm{Vgl}$. den Überblick von Roswitha Reinbothe, Verbreitung der deutschen Sprache in Kaiserreich und Weimarer Republik, in: Ammon (Hrsg.), Sprachförderung, S. 31-41.

69 Die Bezeichnung wurde in Hinblick auf die ursprüngliche Bedeutung des Wortes im Sinne von „werben, verbreiten“ eingeführt, nicht in der nach dem Ersten Weltkrieg aufkommenden Konnotation „politischer Indoktrination“.

70 Kloosterhuis, Friedliche Imperialisten, S. $188 \mathrm{ff}$. sowie Geheime Denkschrift des Auswärtigen Amtes über das deutsche Auslandsschulwesen vom April 1914, abgedruckt in: Düwell, Deutschlands auswärtige Kulturpolitik, S. 268-370.

71 Gerhard Weidenfeller, Der VDA zwischen „Volkstumskampf“ und Kulturimperialismus, in: Interne Faktoren auswärtiger Kulturpolitik im 19. und 20. Jahrhundert, hrsg. vom Institut für Auslandsbeziehungen, Stuttgart 1981, S. 17-26.

72 Düwell, Deutschlands auswärtige Kulturpolitik, S. 128-152. 
Türkei. ${ }^{73}$ Zugleich litt die Verbreitung der deutschen Sprache in den Auslandsschulen nach dem Ersten Weltkrieg daran, daß diese sich immer mehr den nationalen Unterrichtssystemen der Gastländer angleichen mußten, was auch verstärkten Unterricht in der Sprache des entsprechenden Landes bedeutete. ${ }^{74}$ Quantitativ hingegen erholte sich das deutsche Auslandsschulwesen bis 1930 nicht nur von den Schließungen im Verlauf des Ersten Weltkrieges. Die Zahl stieg bis 1931 sogar durch einen forcierten Ausbau auf etwa 1500 Schulen, davon allein ca. 1200 in Brasilien, während es beispielsweise in ganz Europa nur etwa 50 Auslandsschulen gab.

Die Förderung der deutschen Sprache im Ausland war 1928/29, als Thierfelder mit dem Auswärtigen Amt in Verbindung trat, also im Wesentlichen auf den Erhalt bzw. Ausbau der deutschen Auslandsschulen beschränkt. Die Hauptaufmerksamkeit galt wie bereits vor dem Ersten Weltkrieg eher dem Erhalt der Sprachkenntnisse unter den deutschen Minderheiten im Ausland als einer Sprachverbreitungspolitik unter den nichtdeutschen Mehrheitsvölkern der Gastländer. Der Sprachförderung unter erwachsenen Ausländern, der Entwicklung der internationalen Stellung der deutschen Sprache oder der sprachpolitischen Aktivitäten anderer Länder wurde hingegen in der Wilhelmstraße kaum Beachtung geschenkt. Im Jahre 1929 beispielsweise hatte der Leiter der Kulturabteilung des Auswärtigen Amts, Hans Freytag, in der „Deutschen Rundschau“ einen Artikel über die deutsche auswärtige Kulturpolitik veröffentlicht, in dem die Sprachförderung nicht einmal Erwähnung fand. ${ }^{75}$ Bis 1938 gab es in der Kulturabteilung des Auswärtigen Amts auch kein gesondertes Referat zur Förderung der deutschen Sprache im Ausland. Daß die deutschen Diplomaten bis Ende der zwanziger Jahre der sprachpolitischen Betätigung anderer Staaten und der Stellung der einzelnen Fremdsprachen im Ausland keine besondere Aufmerksamkeit zollten, wird aus einer Aufzeichnung der Kulturabteilung vom September 1930 deutlich. Einer ihrer Mitarbeiter hatte sich die Mühe gemacht, die Berichte der Auslandsmissionen der letzten Jahre durchzusehen, die, sofern kulturpolitisch relevant, auch an die Kulturabteilung weitergeleitet worden waren. Er mußte feststellen, daß sich diese Berichte weder den kulturpolitischen Aktivitäten anderer Staaten besonders widmeten noch die Frage des Fremdsprachenunterrichts sowie generell die Stellung fremder Sprachen im Gastland für berichtenswert hielten. ${ }^{76}$ Dieses Ergebnis war insofern nicht erstaunlich, als es bis Ende der dreißiger Jahre an den deutschen Auslandsmissionen keine speziellen Kulturreferenten gab, mithin der Berichterstattung über kulturelle Entwicklungen im Gastland ohnehin nicht viel Zeit gewidmet werden konnte. In einer Aufzeichnung der Kulturabteilung für Reichsaußenminister Julius Curtius hieß es denn auch zu dessen Orientierung, daß die Deutsche Akademie auf Anregung des Auswärtigen Amts die Spracharbeit ins

73 Zahlen nach dem Findbuch der (alten) Kulturabteilung des Auswärtigen Amts.

74 Ammon, Die internationale Stellung der deutschen Sprache, S. 454.

75 Hans Feytag, Über deutsche Kulturpolitik im Ausland, in: Deutsche Rundschau, 55 (1929), S. 97-101.

76 PA Bd. R61125, Aufzeichnung für Terdenge, 3. 9. 1930. 
Zentrum ihrer Aktivitäten gestellt habe, die bislang von keiner Stelle systematisch gepflegt worden sei. ${ }^{77}$

Dank der sprachstatistischen Aktivitäten der Deutschen Akademie, vor allem ihres Generalsekretärs, änderte sich nun aber innerhalb von nur etwa zwei Jahren der Stellenwert der Sprachförderung in der Wilhelmstraße. Die Kulturabteilung übernahm Thierfelders durch - wie es schien - akkurate Erhebungen abgesicherte Interpretation, daß die deutsche Sprache weltweit einen Aufschwung erlebe, der nicht nur eine Normalisierung nach dem durch den Weltkrieg verursachten Einbruch ihrer internationalen Stellung sei. Sie machte sich vielmehr Thierfelders Argument zu eigen, daß man sogar auf Anzeichen einer über die Vorkriegszeit hinausgehende Ausdehnung der deutschen Sprache schließen könne. Mithin sei Sprachförderung ein vielversprechender Ansatzpunkt für die deutsche auswärtige Kulturpolitik. So wie die deutsche Sprache schon das im 19. Jahrhundert dominierende Französisch in Europa entthront habe, bestehe jetzt die berechtigte Hoffnung, bei entsprechenden Anstrengungen das Englische in Europa von Platz eins zu verdrängen. Denn Voraussetzung für die Weltstellung des Englischen war für die Zeitgenossen Großbritanniens Position als uneingeschränkte Welthandelsmacht gewesen. So war vor 1914 allgemein die Auffassung verbreitet gewesen, Französisch sei die Sprache der Diplomatie, Englisch des Handels und Deutsch der Wissenschaft. ${ }^{78}$ Die britische Position als führende Handelsmacht der Welt war aber durch den Ersten Weltkrieg vernichtet worden, während zugleich die überragende Bedeutung der USA durch ihre seit 1920 betont isolationistische Politik nicht in vollem Umfang wahrgenommen oder bewußt verdrängt wurde. Zudem unterschieden sich die Diplomaten in der Wilhelmstraße in ihrer großen Mehrzahl kaum von Thierfelder in ihrer Ablehnung der parlamentarischen Demokratie westlichen Musters, die seit der Etablierung von Heinrich Brünings Präsidialkabinett im Frühjahr 1930 in Deutschland faktisch beendet war. Folglich mußte auch in ihren Augen die Attraktivität der Sprache, die für anti-westliche, "völkische" Ideen stand, zumindest europa-, wenn nicht gar weltweit im Steigen begriffen sein. Im Sommer 1932 hielt dann Thierfelder auch in der Kulturabteilung der Wilhelmstraße einen Vortrag über „Deutsch als Weltsprache“.79

Diese insgesamt sehr optimistische Auslegung der aktuellen Stellung und zukünftigen Perspektiven der deutschen Sprache in der Welt war im Interesse der Deutschen Akademie, die durch eine Konzentration auf die Spracharbeit auf eine Sicherung ihrer Existenz mittels Subventionen vom Reich hoffte. Sie war auch im Sinn der Kulturabteilung, die ein relatives Schattendasein im Gesamtgefüge der Wilhelmstraße führte ${ }^{80}$ und über zu wenig Mittel im Vergleich zu den anderen Staaten klagte. ${ }^{81}$ Höhere Mittel konnte man natürlich um so überzeugender ein-

77 PA Bd. R64194, Vorlage des Leiters der Kulturabteilung für den Reichsaußenminister, 15. 10.1930.

78 Ammon, Die internationale Stellung der deutschen Sprache, S. 283.

79 Dies geht aus einem Schreiben des Auswärtigen Amts vom 13.8. 1932 an die Deutsche Akademie hervor. In: PA Bd. R64194.

80 Twardowski, Anfänge der deutschen Kulturpolitik zum Ausland, S. 18.

81 So der Leiter der Kulturabteilung, Freytag, in einem Schreiben vom 23. 5. 1929 an Georg Schreiber, in dem er einerseits Schreiber für sein Eintreten im Haushaltsausschuß des 
fordern, je mehr man vielversprechende und angeblich statistisch belegte Ansatzpunkte einer Kulturarbeit zum Ausland aufzeigte. Folglich hieß es in einem Redeentwurf der Kulturabteilung für den Reichsaußenminister vom Juni 1930: „Das Rückgrat unserer ganzen Kulturpolitik ist nach meiner Überzeugung die Pflege der deutschen Sprache, deren Weltgeltung unbestritten im Zunehmen ist. " 82 Julius Curtius bedankte sich dann auch bei seinem Auftritt auf der Jahresversammlung der Deutschen Akademie im Oktober 1930 in Berlin, der ersten überhaupt, bei der ein Reichsaußenminister anwesend war, dafür, daß die Akademie den Blick auf die wachsende Bedeutung der deutschen Sprache im Ausland gelenkt habe. ${ }^{83}$ In einem Runderlaß von 1931 wurden die Auslandsmissionen folglich aufgefordert, die Akademie, die mit der Förderung der deutschen Sprache eine besonders wichtige Aufgabe gefunden habe, zukünftig bei ihrer Auslandsarbeit zu unterstützen. ${ }^{84}$

Betrachtet man aus heutiger Sicht die damalige Entwicklung der internationalen Stellung der deutschen Sprache, so lassen sich die zwanziger und frühen dreißiger Jahre, zumindest in Europa, eher als eine Phase der relativen Erholung nach den kriegsbedingten Einbrüchen interpretieren, nicht jedoch als vielversprechender Aufstieg. In den USA beispielsweise erlangte Deutsch als Fremdsprache in den Schulen nie mehr die dominierende Stellung, die es vor 1914 gehabt hatte. Französisch übernahm diese Position. Weltweit verzeichneten im übrigen sowohl das Deutsche wie auch das Französische schon vor 1914 einen leichten Rückgang im Schulunterricht, von dem Englisch profitierte. ${ }^{85}$ Lediglich in Ost- und Südosteuropa mögen tatsächlich Chancen zur Ausweitung der aus historischen, ethnischen und politischen Gründen ohnehin schon starken Stellung der deutschen Sprache bestanden haben. Doch war natürlich die Interpretation, daß Deutsch als Weltsprache noch eine große Zukunft vor sich habe, eine motivierendere und zugleich zur Rechtfertigung der Kulturfonds zugkräftigere Vision als jene einer relativen Stabilisierung oder einer Nullsummenrechnung, bei der Gewinne in gewissen Regionen der Welt Verlusten in anderen gegenüberstanden. Zudem verstellte in Berlin wie München neben budgetären Erwägungen politisches Wunschdenken, gespeist im wesentlichen aus einer Ablehnung der westlichen Zivilisation und ihres Demokratiegedankens, den nüchternen Blick auf die tatsächliche internationale Stellung der deutschen Sprache.

Wie fragwürdig die gesamte Sprachstatistik Thierfelders, vor allem aber die daraus abgeleiteten Entwicklungsperspektiven für die internationale Stellung der deutschen Sprache waren, zeigt seine erste Bestandsaufnahme nach dem Zweiten Weltkrieg aus dem Jahre 1950. Sie zeugt von dem selben Zweckoptimismus hinsichtlich der Zukunft der deutschen Sprache wie die Erhebungen der Jahre 1928

Reichstages dankte, andererseits auf die nach wie vor bestehende finanzielle Überlegenheit der anderen Staaten auf kulturpolitischem Gebiet hinwies. In: PA Bd. R61124.

82 PA Bd. R61125, Entwurf zu der Rede des Herrn Reichsaußenministers betreffend die Aufgaben der Abteilung VI, 10.6.1930.

83 Bericht über die Hauptversammlung der Deutschen Akademie in Berlin 10./11. 10. 1930, in: MdDA, 5 (1930), S. 277-302, hier S. $300 \mathrm{f}$.

84 Scholten, Sprachverbreitungspolitik des nationalsozialistischen Deutschlands, S. 106.

85 Ammon, Die internationale Stellung der deutschen Sprache, S. $427 \mathrm{ff}$. 
bis 1936. Nun führte er z.T. genau das Gegenteil der Gründe, die er 20 Jahre zuvor für die angeblich zunehmende Bedeutung der deutschen Sprache genannt hatte, dafür an, daß Deutsch erneut auf dem Vormarsch sei: Nach Flucht und Vertreibung der Deutschen aus Ost- und Südosteuropa war es plötzlich das Verschwinden dieser deutschsprachigen Minderheiten, welches die Verbreitung des Deutschen im Ausland fördern würde, da durch Wegfall dieser Mittler die Ausländer gezwungen seien, Deutsch zu lernen. ${ }^{86}$ War es in den dreißiger Jahren u.a. das „völkische Prinzip“, das Deutsch angeblich zum Exportschlager machte, so war es nun die Ablehnung des Nationalsozialismus, welche die Verbreitung des Deutschen gefördert habe, da man im Ausland den Gegner habe studieren müssen. In einzelnen alliierten Ländern, vor allem in Nordamerika, habe das Deutsche sichtbare Fortschritte gemacht, so daß es 1950 mehr Deutschsprechende als 1938 gebe, "wenn wir von den Kriegsverlusten absehen". ${ }^{87}$ Thierfelder versuchte also nach 1945 wie schon seit Ende der zwanziger Jahre, Trends herbeizuschreiben, indem er jede militärische und politische Katastrophe Deutschlands in Ereignisse umdeutete, die letztlich der Verbreitung der deutschen Sprache im Ausland förderlich seien. Im Gegensatz jedoch zu den fünfziger Jahren, als Thierfelder zunehmend wie ein deutsch-nationales Fossil erschien, das nicht mehr in die neuen Zeitläufte zu passen schien, ${ }^{88}$ verfehlten seine Sprachprognosen Ende der zwanziger/ Anfang der dreißiger Jahre nicht ihre Wirkung im Auswärtigen Amt, das seinerseits energisch an der Wiederherstellung der deutschen Großmachtstellung arbeitete. Sie waren entscheidend dafür, daß die Deutsche Akademie sich endlich ein Tätigkeitsfeld sicherte, für welches sie in den kommenden Jahren staatliche Unterstützung erwarten konnte.

86 Franz Thierfelder, Deutsche Sprache im Ausland, in: Deutsche Philologie im Aufriß, Bd. 1, hrsg. von Wolfgang Stammler, Berlin u. a. 1952, S. 499-581, hier S. 502.

87 Ebenda., S. $544 \mathrm{f}$

88 So sah der neue Leiter der Kulturabteilung des Auswärtigen Amts, Dieter Sattler, 1959 Thierfelder als zu deutsch-national und damit den Generalsekretär des IfA als potentiell ungeeignet an, eine der Mittlerorganisationen der bundesrepublikanischen auswärtigen Kulturpolitik zu leiten. Vgl. Stoll, Kulturpolitik als Beruf, S. 370. 